\title{
Investigating the Behavior of Idiosyncratic Volatility *
}

\author{
Yexiao $\mathrm{Xu}$ \\ School of Management \\ The University of Texas at Dallas \\ Burton G. Malkiel ${ }^{\dagger}$ \\ Economics Department \\ Princeton University
}

September 3, 2001

\begin{abstract}
This paper studies the behavior of idiosyncratic volatility for the post war period. Using aggregate idiosyncratic volatility statistics constructed from the Fama and French (1993) three-factor model, we find that the volatility of individual stocks appears to have increased over time. This trend is not solely attributed to the increasing prominence of the NASDAQ market. We go on to suggest that the idiosyncratic volatility of individual stocks is associated with the degree to which their shares are owned by financial institutions. Finally, we show that idiosyncratic volatility is also positively related to expected earning growth.
\end{abstract}

*This work was supported by the Princeton University Center for Economic Policy Studies

${ }^{\dagger}$ We are grateful to John Y. Campbell, Jennifer Conrad, Francis X. Diebold, Charles Jones, Robin L. Lumsdaine, Albert Madansky (the editor), Jianping Mei, René Stultz, the anonymous referees, and seminar participants at the 2000 American Finance Association conference for extremely helpful comments. The address of the corresponding author: School of Management, the University of Texas at Dallas, Box 830688, Richardson, Texas 75083. Email: yexiaoxu@utdallas.edu 


\title{
Investigating the Behavior of Idiosyncratic Volatility
}

\begin{abstract}
This paper studies the behavior of idiosyncratic volatility for the post war period. Using aggregate idiosyncratic volatility statistics constructed from the Fama and French (1993) three-factor model, we find that the volatility of individual stocks appears to have increased over time. This trend is not solely attributed to the increasing prominence of the NASDAQ market. We go on to suggest that the idiosyncratic volatility of individual stocks is associated with the degree to which their shares are owned by financial institutions. Finally, we show that idiosyncratic volatility is also positively related to expected earning growth.
\end{abstract}

Key Words: Earning Growth, Factor Model, Idiosyncratic Volatility, Institutional Ownership, Rolling Regression. 


\section{Introduction}

Considerable attention has been given in the financial press to the increase in stock market volatility during the late 1990s. The facts suggest, however, that this attention has been misplaced. As shown first by Schwert (1989), no long-run uptrend is evident for the volatility of the market as a whole. The volatility of the market during the late 1990s, while larger than it was earlier in the decade, was still considerably below the volatility recorded during earlier periods of the century.

What has received far less attention is the behavior of the volatility of individual stocks. The volatility of individual stocks can increase even when the volatility of the market as a whole remains stable as long as correlations among stocks are declining. In this study, we show, from a different perspective and using different measures from those used by Campbell, Lettau, Malkiel, and Xu (2001), that volatilities of individual stocks have indeed increased over the decades of the 1980s and 1990s. When the total volatility of individual stocks is decomposed into systematic volatility and idiosyncratic volatility, we present clear evidence that idiosyncratic volatility has trended up. We find that our result is not solely attributable to the increasing prominence of the NASDAQ market. Most importantly, we find from cross-sectional regressions that the volatility of individual stocks may be related to the amount of institutional ownership and to the firms' objectives in pursuing high growth.

While idiosyncratic volatility can be eliminated in a well- diversified portfolio, individual investors may still care about the specific risk of the securities they hold. Because of wealth constraints or by choice, many investors do not hold diversified portfolios. Those investors might feel the risk of their portfolios has increased when idiosyncratic volatility is rising. Moreover, high idiosyncratic volatility could increase potential total transactions costs if investors with relatively limited means choose to

achieve adequate diversification. This is so because an increase in idiosyncratic volatil- 
ity will have an important effect on increasing the number of securities one must hold to achieve reasonably "full" diversification. Idiosyncratic volatility is also important to arbitrageurs and option traders where total profits depend on total volatility instead of market volatility. Empirically, Malkiel and Xu (2000) have shown that idiosyncratic volatility can explain cross-sectional differences in the returns from individual stocks.

This paper investigates the mechanisms behind the increase in idiosyncratic volatility during the 1980s and 1990s. Besides the increasing prominence of the NASDAQ market, two important attributes of individual stocks-institutional ownership and high growth-appear to be associated with idiosyncratic volatility. In this paper, we argue why these variables should be related. We then present a cross-sectional study of the relationship between institutional ownership, growth, and idiosyncratic volatility and find strong evidence supporting our hypotheses.

Since idiosyncratic volatility is unobservable and model dependent, we also study similarities and differences between the indirect approach of Campbell, Lettau, Malkiel, and $\mathrm{Xu}$ (2001) and a direct approach utilizing Fama and French (1993) three-factor model in decomposing total volatility. Furthermore, we extend the sample period to cover the entire post war period by using monthly returns instead of daily returns, and we estimate conditional volatility (see French, Schwert, and Stambaugh, 1987) rather than realized volatility. ${ }^{1}$ Interest in understanding time varying conditional volatility has encouraged a large literature based on $\mathrm{ARCH}$ and stochastic volatility models (see Ghysels, Harvey, and Renault, 1997; Bollerslev, Engle, and Nelson, 1994; and Bollerslev, Chou and Kroner, 1992). On the aggregate level, we know that conditional volatility seems to be very persistent, i.e., a large volatility shock seems to persist. Here, we focus on the level of volatility not only at the market level but also at the individual firm level. In order to balance the efficiency in estimating volatility suggested by the

\footnotetext{
${ }^{1}$ Also related to our work is the article by Braun, Nelson, and Sunier (1995). Their emphasis is on the predictive asymmetry in both conditional volatilities and conditional beta estimates.
} 
$\mathrm{ARCH}$ literature and by computational feasibility, we use a rolling regression method in the spirit of Foster and Nelson (1996) to estimate volatility instead of the GARCH approach. We will show that any differences with the GARCH approach are small.

There is growing interest in recent studies that focus on estimating volatility from "ultra-high frequency" (i.e. transaction level) returns. Similar to what has been applied in low frequency return studies, two approaches have been used in estimating the latent volatility of returns. "Ultra-high frequency" data are fundamentally irregularly spaced. Using an autoregressive conditional duration (ACD) model introduced by Engle and Russell (1998) to estimate the arrival rates, Engle (2000) has estimated "ultra-high frequency" GARCH models to measure the price volatility of IBM stock using transactions data. ${ }^{2}$ Although this first approach depends on model specification, it retains all the information in the data. The second approach has been proposed by Andersen, Bollerslev, Diebold, and Ebens (2001) to estimate ex post realized daily volatility of the component stocks of the Dow Jones Industrial Average by summing squares and cross-products of "ultra-high frequency" returns. This approach is model independent and computational efficient. Researchers have also tried to improve the volatility estimate by modeling the microstructure variables simultaneously, such as the cost of market making and intraday periodicity (see Hasbrouck, 1999; and Andersen and Bollerslev, 1997). In all these studies, the emphasis has been on the persistence of volatility.

This paper is organized as follows. In Section 1 we briefly discuss our methods for decomposing total volatility into its systematic and idiosyncratic components, for estimating conditional volatility, and for testing the volatility trend. Section 2 presents our empirical results. The importance of NASDAQ stocks is discussed in Section 3. In Section 4, we provide evidence that the volatility of individual stocks and the proportion

\footnotetext{
${ }^{2}$ Engle and Russell (1997) have also applied ACD modeling approach to foreign exchange data in order to obtain estimates of the instantaneous intensity of price changes.
} 
of the stocks outstanding shares owned by institutions are related. Section 5 studies the relationship between expected earning growth and idiosyncratic volatility. Concluding comments are presented in Section 6. 


\section{The Data and Methodology}

Most of the time series data used in this study are constructed from the 1998 version of the CRSP (Center for Research in Security Prices) tape that includes NYSE/AMEX/ NASDAQ stocks. As is now common in the literature, we focus on the post WWII sub-sample. Because of the change in the interest-rate regime following the Accord of the Treasury and Federal Reserve in 1951, our post WWII sub-sample starts in January 1952 (see Campbell, 1991). In our analysis, both exchange traded stocks (New York Stock Exchange (NYSE) and American Stock Exchange (AMEX)) and the NASDAQ data file are used. The $S \& P 500$ index portfolio studied here is approximated by a so called simulated " $S \& P$ 500" portfolio, which is constructed by value weighting the largest 500 stocks. $^{3}$

\subsection{Measuring Idiosyncratic Volatility}

The idiosyncratic volatility of a stock is unobservable. Moreover, since it is estimated relative to the systematic returns of the stock, it is model dependent. In this paper, we study the behavior of idiosyncratic volatility constructed using two different approaches.

\subsubsection{An Indirect Decomposition Method}

Denote the excess return for stock $i$ relative to the risk-free rate as $R_{i, t}$ and the market excess return as $R_{t}^{M}$. Campbell, Lettau, Malkiel, and Xu (2001) proposed an indirect approach to estimate the realized idiosyncratic volatility. We show in the appendix that a similar approach can be adopted to estimate the conditional aggregate idiosyncratic

\footnotetext{
${ }^{3}$ We use a simulated series because we did not have composition data for the $S \& P 500$ in all periods. We also took returns for the actual $S \& P 500$ index series directly from CRSP data file. There are hardly any differences between these two indices in terms of their calculated volatility, which is the major concern of this study
} 
volatility in the following way,

$$
\hat{v}_{I, t}^{2}=\hat{v}_{A, t}^{2}-\hat{v}_{M, t}^{2},
$$

where $\hat{v}_{A, t}^{2}=\sum_{i=1}^{N} w_{i} \hat{\operatorname{Var}}{ }_{t}\left(R_{i, t}\right)$ is the conditional aggregate volatility calculated from the value weighting of estimates of each individual stock's conditional variance, and $\hat{v}_{M, t}=\hat{\operatorname{Var}_{t}}\left(R_{t}^{M}\right)$ is the estimated conditional volatility of market returns. This approach is easy to implement and is less dependent on specific models. While the estimates may be biased under certain models, such biases tend to be small empirically as we show in the Appendix.

\subsubsection{The Direct Decomposition Method}

An alternative approach would be to simply estimate idiosyncratic volatility using residuals from a factor model. As has been made popular by Fama and French (1993), a three factor model which includes the market return, the return proxy for size $\left(R_{t}^{S M B}\right)$, and the book-to-market return proxy $\left(R_{t}^{H M L}\right)$ appears to be more effective in explaining returns than the CAPM. ${ }^{4}$ Therefore, we will also fit the following model to individual stocks:

$$
R_{i, t}=\beta_{i}^{M} R_{t}^{M}+\beta_{i}^{S M B} R_{t}^{S M B}+\beta_{i}^{H M L} R_{t}^{H M L}+r_{i, t}
$$

In this case, the conditional aggregate idiosyncratic volatility can be estimated as, ${ }^{5}$

$$
\hat{v}_{I, t}^{2}=\sum_{i=1}^{N} w_{i} \operatorname{Var}_{t}\left(r_{i, t}\right) \text {. }
$$

As a practical matter, even if one accepts the factor model, it is difficult to estimate an individual stock's betas over a short period of time. Such beta estimates are critical

\footnotetext{
${ }^{4}$ Ferson and Harvey (1999) have argued that the three factor model may still fail in a conditioning framework. However, for our purpose, this is a reasonable alternative for constructing an idiosyncratic volatility series.

${ }^{5}$ We are grateful to Eugene Fama for making these data available to us.
} 
in computing idiosyncratic volatility. Therefore, both the indirect and direct methods for constructing idiosyncratic volatility are applied in this study.

The conditional volatility for each underlying security (or for a market index) can be estimated using the standard deviation of the stock's periodic returns. However, since volatilities are persistent, as we have learned from the ARCH literature, such an estimator of volatility will be biased and inefficient, as shown by Chou (1988). In principle, one should adopt a GARCH type of volatility estimator. Because of the computational intensity of such an estimator, however, this strategy is not feasible in our study where we focus on individual securities. Instead, we use rolling regression estimators with window length $\tau$, namely

$$
\begin{aligned}
\hat{\operatorname{Var}}_{t}\left(R_{t}^{M}\right) & =\sum_{k=1}^{\tau} \omega_{k}\left(R_{t+1-k}^{M}-\mu_{t}^{M}\right)^{2} \\
\hat{\operatorname{Var}}_{t}\left(R_{i, t}\right) & =\sum_{k=1}^{\tau} \omega_{k}\left(R_{i, t+1-k}-\mu_{i, t}\right)^{2}
\end{aligned}
$$

where $\mu_{t}^{M}=\sum_{k=1}^{\tau} \omega_{k} R_{t+1-k}^{M}$ and $\mu_{i, t}=\sum_{k=1}^{\tau} \omega_{k} R_{i, t+1-k}$. The weights $\omega_{k}$ decline geometrically with $\sum_{k=1}^{\tau} \omega_{i}=1$, and $\tau$ represents the window length ${ }^{6}$.

\subsection{Rolling Methods of Estimating Volatility Compared with GARCH Techniques}

When using rolling methods to estimate volatility, Monte Carlo simulations are needed to choose the window length or decay rate in order to best preserve the volatility characteristics. ${ }^{7}$ Motivated by GARCH estimators, which are infinite rolling regression estimators, we investigated a finite rolling estimator with geometrically declining weights of $\rho^{k}$. We denote this estimator as using the first type of geometric weights.

\footnotetext{
${ }^{6}$ Using these estimators of conditional volatility, equation (14) in the Appendix may not hold if past $R^{M}$ helps to predict current $r_{i}$ and vice versa. Fortunately, this is not the case here since $r_{i}$ is an idiosyncratic return.

${ }^{7}$ Since volatility is unobservable, statistical inferences based on estimated volatility may be biased as suggested by Ghyseis and Perron (1993).
} 
In addition, we also studied a second type of geometrically declining weights $\left(e^{-\alpha k}\right)$ proposed by Foster and Nelson (1996). ${ }^{8}$ Foster and Nelson have also suggested that optimal $\alpha$ and $\tau$ have a relationship of $\tau / \alpha=\sqrt{3}$.

We determined the choice of $\rho$ and $\tau$ through Monte Carlo simulations by assuming that the data generating process for volatility is a $\operatorname{GARCH}(1,1)$ process. In particular, a $\operatorname{GARCH}(1,1)$ model of the form $h_{t}=\kappa+\delta h_{t-1}+\phi\left(r_{t-1}-\mu\right)^{2}$ is fitted to the value weighted monthly NYSE/AMEX/NASDAQ index return $r_{t}$ during the period 1952 to 1998. We obtained the following parameter values: $\kappa=0.9348 \times 10^{-4}, \delta=0.8586$, $\phi=0.0880$, and $\mu=.0107$, which implies an unconditional monthly standard deviation of $4.18 \%$. Based on these estimates, we generated stock return data over the same time horizon with an added time trend in the volatility, i.e.,

$$
\begin{aligned}
R_{t} & =u_{t} \\
u_{t} & =\sqrt{h_{t}} \nu_{t}
\end{aligned}
$$

where

$$
\begin{aligned}
& \nu_{t} \sim N(0,1) \\
& h_{t}=\kappa+\gamma t+\delta h_{t-1}+\phi u_{t-1}^{2},
\end{aligned}
$$

specify the structure of conditional volatility. To be comparable with the average trend found in our empirical study, we set $\gamma=2 \times 10^{-6}$. When $h_{t}$ is known, statistical inference can be drawn on the $\gamma$ estimate. However, there are two potential problems. First, since equation (9) can be rewritten as,

$$
\begin{aligned}
h_{t} & =\kappa+\gamma t+(\delta+\phi) h_{t-1}+\xi_{t}, \\
\xi_{t} & =\phi h_{t-1}\left(\nu_{t-1}^{2}-1\right),
\end{aligned}
$$

an OLS regression based on equation (10) is inefficient due to heteroscedastic residuals. Therefore, a generalized least squares regression should be employed. Fortunately, the

\footnotetext{
${ }^{8}$ Two sided rolling regressions may be optimal in maintaining the persistence of volatility, but they do poorly in detecting a time trend. Therefore, only a one sided rolling regression has been employed.
} 
residuals and the regressor are independent, and we can use weighted least squares with weights of $\sqrt{h_{t-1}}$. Second, as shown by Canjels and Watson (1997), the $t$ - ratio on the $\gamma$ estimator will not have the right size when $h_{t}$ is very persistent. Further investigation on the critical values and the bias involved is therefore warranted. In a separate simulation, we studied the biases in the GLS estimators when the true volatility is known. On the one hand, when the true persistence is high the slope coefficient on the linear trend $\gamma$ is biased upward even with a large sample. ${ }^{9}$ The bias disappears, however, when persistence is less than .9 with a sample size of more than 2000. On the other hand, the persistence estimates are biased downwards and are largely dependent on the sample size. In addition, the $t$ values necessary for rejecting the hypothesis of a zero trend are larger than the conventional $t$-ratios but they tend to be very close for large samples.

\section{Insert Table 1}

Similar simulations were conducted in order to determine the best structure for the rolling estimator. We used a sample size of 564 with $\rho=.8, .85, .9, .95$ and with window lengths of 12 and 24, respectively, for the first type of geometric weights. We also tried the second type of geometric weights with window lengths $\tau=6,12,18,24$. An $\operatorname{AR}(1)$ model with a trend similar to equation (8) is then fitted to each estimated volatility series using a GLS procedure. We report the distributions for the $\hat{\gamma}$ estimator and the $\hat{\theta}$ estimator in Table 1. Generally speaking, the $\hat{\gamma}$ estimator can be biased either upward or downward. At a high persistence level, the first type of weights with a window length of 12 seems to induce more upward bias than that of window length 24 which is more conservative at a low persistence level. We therefore chose a window length of 24 for the first type of weights. Furthermore, we used $\rho=.90$ since it produces almost no bias at a high persistence level and is very conservative at a low persistence level.

\footnotetext{
${ }^{9}$ The problem is more severe if simple OLS estimators are used.
} 
However, it seems that the persistence estimator $\hat{\theta}$ is biased upwards most of the time. Therefore, a second type of geometric weights with $\tau=12$ was used. This particular weighting scheme worked best in terms of preserving persistency though it is biased upward when the true volatility is highly persistent. In order to balance the two biases, both types of weighting schemes were used in our empirical study.

\section{Insert Table 2}

Due to the persistence of volatility, the conventional critical value for a $t$-test will not have the right size using GLS. Therefore, for our sample size $(\mathrm{T}=564)$, we have computed critical values at different significance levels for volatility with different persistence. Table 2 reports these critical values using the first type of weights with $\rho=0.85$ and $\rho=0.90$ as well as using the second type of weights with $\tau=12$ and $\tau=18$. In general, the critical values are larger using the second type of weights with $\tau=12$ than the conventional level. The same is true under the first type of weights with $\rho=.9$. It is also interesting to note that when volatilities are less persistent, the critical value using first type of weights with $\rho=.9$ is a little smaller than that of the conventional level. This may be due to the fact that this type of estimator is very conservative.

\subsection{Testing the volatility trend}

As the discussion in the previous section suggests, a generalized least squares regression should be applied when volatilities are generated from a $\operatorname{GARCH}(1,1)$ process with a trend. We estimated the following model using GLS, ${ }^{10}$

$$
v_{t}=\mu+\rho v_{t-1}+\gamma t+\alpha_{1} \Delta v_{t-1}+\cdots+\alpha_{p} \Delta v_{t-p}+\epsilon_{t}
$$

\footnotetext{
${ }^{10}$ This is in the spirit of an augmented Dickey-Fuller regression to allow for general structure of correlations.
} 
where the $v_{t}$ are the volatility estimates. In this case, the null hypothesis is that $\gamma \geq 0$. Alternatively, under a general structure of volatility, we can examine if trends exist in the framework of unit root tests with trend. ${ }^{11}$ However, it is well known that the conventional $t$ statistics are invalid on trend estimates. Instead, we will apply Vogelsang's (1998) Wald type of tests based on the following model,

$$
\begin{array}{r}
\log \left(v_{t}\right)=\mu+\rho \log \left(v_{t-1}\right)+u_{t}, \\
u_{t}=\alpha u_{t-1}+d(L) e_{t},
\end{array}
$$

together with some initial conditions and $d(L)=\sum_{i=0}^{\infty} d_{i} L^{i}$. These tests are robust to both $\mathrm{I}(0)$ and $\mathrm{I}(1)$ errors. However, since we do not believe volatility should follow a random walk (i.e., an $\mathrm{I}(1))$ process as a prior, we use a $t-\mathrm{PW}^{1}$ test to preserve the best power. ${ }^{12}$ In particular, we constructed a corresponding $90 \%$ confidence interval of a linear trend on the logarithm of volatility. Stated another way, we can say that there is positive growth in volatility if the confidence interval is on the positive orthoaxis.

\footnotetext{
${ }^{11}$ Due to the non-negativity of volatility, we will use a log volatility measure.

${ }^{12}$ Vogelsang (1998) provided a detailed discussion on the power of his test. We are indebted to him for supplying the GAUSS code of the test.
} 


\section{The Empirical Results}

It is not uncommon on a single trading day to find that several stocks have changed in price by $25 \%$ or more. Indeed, price changes of more than $50 \%$ in a single day for some stocks (excluding new issues) are not at all uncommon. A natural starting point to investigate the behavior of volatility of individual stocks is to examine the volatilities of the most volatile stocks. Later, we study the volatility characteristics of idiosyncratic risk using two different approaches.

\subsection{The Volatility of Individual Stocks}

There appear to be obvious patterns of increasing volatility for individual stocks. On any specific day, the most volatile individual stocks move by extremely large percentages. It appears that when earnings of companies are reported that differ slightly from the forecasts of Wall Street analysts, or when companies warn the financial community that earnings may not meet forecasted levels, the market reaction is immediate and usually substantial as institutional investors seem likely to interpret the news in a similar fashion. The question remains whether such impressions from casual empiricism can be documented rigorously and, if so, whether these patterns of volatility for individual stocks are different from those existing in earlier periods.

\section{Insert Figure 1}

Figure 1 measures the daily volatility (the standard deviation of daily returns) ${ }^{13}$ of the 20 stocks on the CRSP tape each month with the largest percentage price fluctuations for that month during the period 1963 to 1998. To put the volatility numbers in perspective, we plot at the bottom of the graph five times the daily volatility

\footnotetext{
${ }^{13}$ We adopt such a measure here simply because it corresponds to the way stock traders look at volatility and provides a useful summary descriptive statistic.
} 
of the Standard and Poor's 500 Index computed in the same way. Similar pictures are drawn for the 50 most volatile stocks as well as the top 10 and 27 percent of stocks in terms of measured volatility. As shown by Lys and Sabino (1992), the power of certain tests is maximized by comparing the mean values in the extreme-ranked groups when each group contains $27 \%$ of the sample. As summarized in the first panel of Table 3 , the most volatile stocks display volatility many times that of the index. For example, the average volatility of the top 20 most volatile stocks is 40 times that of the average market index in the '90s. Even the top $10 \%$ most volatile stocks fluctuated more than the market index in the '90s by a factor of 15 . But what is striking about the analysis is that when we plot the volatility of different groups of the most volatile stocks over time, there does seem to be an upward drift not seen in the plot of volatility for the market as a whole. The average volatility of the 20 (or 10\%) most volatile stocks in the '90s is three (or two) times as volatile as it was in the '60s. Furthermore, by using a proportional measure (such as top $10 \%$ or top $27 \%$ ) we can guard against the possibility that when our findings show increasing volatility are simply the result of an increased number of companies in the sample. ${ }^{14}$

\section{Insert Table 3}

It does appear that price changes for the most volatile stocks (which are typically displayed in the financial pages of major newspapers) have increased in amplitude, especially during the 1980s and 1990s. The upward trend in volatility for the most volatile stocks is not due to the volatility persistency shown in our trend test, although the autoregressive coefficients $\theta$ in Table 4 are all very large. ${ }^{15}$ In all four cases shown, we reject the hypothesis of no deterministic trend in the volatility series at about the

\footnotetext{
${ }^{14}$ One might argue that if volatility is drawn from some fixed distribution and we increase the number of draws over time, the upper tail will be more volatile for just this reason.

${ }^{15}$ In addition to AIC and BIC criteria, we use twelve lags in the times series model to account for possible seasonality.
} 
$1 \%$ significance level using our $t$-type test based on GLS estimates. The robust $90 \%$ confidence intervals are well above zero. In particular, for the portfolio of 20 most volatile stocks, the standard deviation in the returns of those stocks increases about $0.0215 \%(=.0047 \sqrt{21})$ a month, while the monthly growth rate of this volatility, using Vogelsang's (1998) model in equation (12), is about .0219\% over the $1963-1997$ period. ${ }^{16}$ Although these numbers decrease when we include more stocks, as shown in Table 4, they remain statistically significant in both tests.

\section{Insert Table 4}

We have also looked at the other extreme and tested for any tendency for the volatility of the least volatile stocks (measured either in number or in percentage) to have increased or decreased over time. There has been no tendency for the most stable stocks to exhibit either an upward or downward trend in volatility over time.

From a statistical point of view, when there are more firms with volatile returns in the sample, the probability that we will observe large deviations from the mean will increase. It might be conjectured, therefore, that our findings are simply an artifact of the fact that over time our sample is likely to include an increasingly larger number of small companies. The measured volatility of small-company stocks may be larger either because of their small size or because of the larger bid-asked spreads associated with such companies. We tested this hypothesis by examining our sample of most volatile stocks to insure that the size characteristics of such stocks had not changed over time. We found that the size of the "most volatile stocks," however measured, has not decreased over time. Moreover, the relative size of samples of various percentages of the most volatile stocks, compared with the total market capitalization of all stocks,

\footnotetext{
${ }^{16}$ Vogelsang's test is based on log standard deviations. In order to be comparable with our estimate, it is converted according to $\sqrt{21} * .00312 * \bar{v}(1-\theta)$, where $\bar{v}=\frac{\mu+.5 * T \gamma}{1-\theta}=\frac{.0052+.5 * 432 * .000047}{1-.923}=19.93 \%$ is the average mean estimate.
} 
has actually increased during recent periods. Thus, companies of constant absolute and relative size have actually become more volatile over time.

\subsection{The Volatility Level in Each Decade}

In the second panel of Table 3, we compute the average conditional volatility under different weighting schemes for NYSE/AMEX/NASDAQ stocks. Despite the preceding evidence on the most volatile stocks and despite popular perception, the remarkable fact is that the average monthly market volatility in the ${ }^{\prime} 90$ s is about $3.3 \%$, which is not much different from those in the ${ }^{\prime} 50$ s or ${ }^{\prime} 60 \mathrm{~s}$. Although the average market volatility in the ${ }^{\prime} 70$ s or ${ }^{\prime} 80$ s seems to have increased from the ${ }^{\prime} 50$ s or ' 60 s, a careful examine of the dashed line in the top panel of Figure 2 suggests that the increase is largely due to the oil shock and the 1987 stock market crash. Volatility then quickly receded after these two events. There is no evidence that increased market volatility has accompanied the growth of derivative market or the increased institutionalization of the stock market during the decades of ' 80 s and '90s.

\section{Insert Figure 2}

In contrast, the value weighted total volatility of individual stocks on the CRSP tape has been around $8 \%$ in the two most recent decades compared with about $6 \%$ in the earlier decades. This aggregate volatility is defined in equation (15) and can be viewed as the overall volatility of a typical stock. It can be further demonstrated by the solid line in the top panel of Figure 2. If we remove the two sharp spikes in volatility during the oil shock and the 1987 stock market crash, there is an apparent upward trend. Note also that the estimates based on different weighting schemes are virtually the same. 


\subsection{The Characteristics of Idiosyncratic Volatility}

Volatility itself fluctuates greatly from time to time. Simple averages can not describe the behavior of the entire volatility series. In this section, we focus on the persistence and trend in volatility and examine the idiosyncratic volatility estimates using direct and indirect methods.

The casual observation about market volatility can be further demonstrated by estimating a trend. Table 5 shows that the trend coefficients $\gamma$ are not close to being significant for the market as a whole using the critical values in Table 2. Furthermore, the robust confidence interval ranges from -.07\% to .21\% for NYSE/AMEX/NASDAQ index volatility. The conclusion that a trend does not exist is therefore very robust whether we use the first or second type of geometric weights. The series is fairly persistent since the autoregressive coefficient $\theta$ tends to be large (above .9). Therefore, we conclude that both volatility series appear to be stationary and the original findings of Schwert continue to hold into the 1990s.

\section{Insert Table 5}

The low volatility numbers for the market as a whole seem at odds both with our findings for the volatility of the most volatile stocks and the descriptive statistics for the total volatility of a typical stock. Campbell, Lettau, Malkiel, and Xu (2001) have argued that the difference could lie in the behavior of idiosyncratic volatility of the individual component stocks. Although their conclusion of an upward trend in the idiosyncratic volatility is based on realized volatilities, applying their indirect method to compute conditional volatility, we find a similar trend. The indirect estimates of idiosyncratic volatility have gone up from $4.7 \%$ in the ${ }^{\prime} 50$ s to $7.2 \%$ in the ${ }^{\prime} 90$ s-a more than $50 \%$ increase. While the average idiosyncratic volatilities are comparable in the '80s and '90s, there are large increases in each of the preceding decades. As proposed in 
Section 1, we have also constructed idiosyncratic volatility directly from the residuals of the Fama and French (1993) three-factor model. In particular, each month, we first fit the three-factor model to each stock using current and previous 35-month return data. We then apply the same rolling method to estimate the idiosyncratic volatility from the estimated residuals for each of the stocks. Finally, we aggregate the idiosyncratic volatility of individual stocks using value weighting. It is interesting to see that the pattern remains although the direct estimate of idiosyncratic volatility is $10 \%$ lower than that of the indirect estimate on average.

In the second half of Figure 2, we have plotted the aggregate idiosyncratic volatility estimates for the NYSE/AMEX/NASDAQ composite index portfolio using the second type of geometric weights. We see visually that the dotted line representing the indirect estimates of idiosyncratic volatility is always above the direct estimates (the solid line). If we accept the three-factor model, the indirect estimate of idiosyncratic volatility seems to be upward biased. Fortunately, both volatility lines appear to increase over time. Therefore, the basic conclusion of increasing idiosyncratic volatility remains. A similar pattern emerges when using different weighting schemes.

The similarity between the direct and indirect estimates of idiosyncratic volatility can be shown from our trend test. As Table 5 indicates, both $\hat{\gamma}$ trend estimates are significant at a $5 \%$ level using either the first or second types of geometric weights. The robust confidence intervals are again above zero. Therefore, no matter how we measure the idiosyncratic volatility, the basic findings of Campbell, Lettau, Malkiel, and $\mathrm{Xu}$ (2001) are supported. At the same time, except for the persistence of the conditional idiosyncratic volatilities, the indirect estimate seems to produce higher mean $(\hat{\mu}=.17 \%)$ than that of the direct estimate $(\hat{\mu}=.13 \%)$. Moreover, the growth rate in the indirect aggregate idiosyncratic volatility estimate $(.00026 \%)$ is about $30 \%$ larger than that of the direct estimate (.00020\%). In both cases, the second type of geometric weighting scheme tends to produce slightly less persistent but faster growing 
idiosyncratic volatility estimates. While the characteristics of idiosyncratic volatility estimates may differ depending on the construction method, we conclude that these tests provide further evidence of increasing idiosyncratic volatility over time. 


\section{Trading NASDAQ Stocks}

Given the empirical results in the previous section, it is natural to ask why the volatility of individual stocks has increased. Campbell, Lettau, Malkiel, and Xu (2001) have explored several explanations, including the break up of conglomerates, early listing of companies in their life cycle, and a leverage effect. However, the increasing volatility of individual stocks may simply reflect the increasing share of trading in the NASDAQ market. The CRSP tape started recording NASDAQ stocks in December 1972. Since then the total number of NASDAQ stocks has gone up from 1,700 stocks in 1975 to 3,200 stocks at the end of 1998. Meanwhile, listed stocks have increased from 2,400 stocks to 3,800 stocks over the same time period. Moreover, NASDAQ trading volume now regularly exceeds the volume traded on the NYSE and AMEX, although comparison may not be exact since some NASDAQ volume may be double counted. Traditionally, smaller stocks and those with high growth stocks such as technology companies are traded on the NASDAQ market. Those stocks tend to be more volatile than the stocks traded in the listed exchanges. In this section, we study the unique characteristics of NASDAQ stocks.

\section{Insert Figure 3}

Since we need two years of monthly returns to compute conditional volatilities, our idiosyncratic volatility estimates start from 1995. Using the same approaches as in the previous section, we have constructed the direct and indirect estimates for idiosyncratic volatilities. It appears that the direct approach produces more conservative estimates than the indirect approach. We have plotted the direct idiosyncratic volatility estimates for NASDAQ stocks in Figure 3 (the dotted line). Although they are value-weighted estimates, the overall level is much higher than for listed stocks over the same time period. For example, from Table 3 we see that average volatility is about $10 \%$ for 
NASDAQ stocks compared with $5.8 \%$ for listed stocks. The second observation from Figure 3 is the apparent trend in idiosyncratic volatility line for NASDAQ stocks from the ${ }^{\prime} 70$ s to the ' 90 s. Table 3 confirms this observation with average volatility estimates of $7.8 \%$ for the ${ }^{\prime} 70 \mathrm{~s}$ and $9 \%$ for the ${ }^{\prime} 80 \mathrm{~s}$.

\section{Insert Table 6}

The same type of GLS test and Vogelsang test can be performed on these idiosyncratic volatility estimates. In Panel $\mathrm{C}$ of Table 6, we report the test results. No matter how we measure the idiosyncratic volatilities, they are much less persistent than the volatility for the total market. At the same time, there exists a very large and significant time trend in the idiosyncratic volatility for the NASDAQ sample. However, the magnitude for the trend estimates is about $60 \%$ larger using the indirect approach than the direct approach.

The interesting question is how the much larger idiosyncratic volatility of NASDAQ stocks contributes to overall aggregate market idiosyncratic volatility. The dashed line in Figure 3 indicates that the idiosyncratic volatilities for the listed stocks are fairly stable after 1984. It is surprising to see that idiosyncratic volatility is not much higher during the stock market crash of 1987 than any other period. Idiosyncratic volatilities are especially high during the oil shock of 1975 and the first half of the '80s when there was a major restructuring movement in American industry. Therefore, it is important to test for a trend in idiosyncratic volatility over our whole sample period for NYSE/AMEX stocks only. Comparing the results reported in Panel B of Table 6 with the corresponding results in Table 5, we see that the persistence of idiosyncratic volatility is virtually unchanged. The $G L S$ test indicates that we are still able to reject the hypothesis of no time trend at a $5 \%$ significance level even though the evidence from the robust confidence interval is somewhat weak. However, the growth rate in 
idiosyncratic volatility is about $40 \%$ lower than before. Therefore, NASDAQ stocks do have significant impact on the idiosyncratic volatility trend.

Of course, it is not justifiable to exclude NASDAQ stocks. There are many extremely large company stocks traded on NASDAQ market, such as Microsoft, Intel, and Cisco Systems to name a few. These are companies that are leaders in their industries. Thus we need also to investigate the volatility of large companies alone. In particular, we will examine the (simulated) $S \& P 500$ portfolio that includes 500 of the largest companies (in terms of their capitalization). As shown in Table 3, the volatility of this index portfolio is very close to that of the NYSE/AMEX/NASDAQ composite index. But the aggregate idiosyncratic volatility estimates seem to be lower over the same time period. The trend test results are summarized in Panel A of Table 6 . For both the direct and indirect estimates of idiosyncratic volatility series, the GLS based $t$ type of test shows that a deterministic time trend is significant at a $5 \%$ level when using either the first type or the second type of geometric weights. At the same time, both robust confidence intervals are above or almost above zero. Furthermore, compared to the results for NYSE/AMEX stocks only in Panel B, we see that they have the same persistence level. However, the growth rate for idiosyncratic volatility is $10 \%$ higher than that of the NYSE/AMEX stocks. Therefore, large stocks rather than small stocks appear to play an important role in the trend of idiosyncratic volatility. 


\section{Institutional Ownership}

Here we examine our conjecture that the increased importance of institutional investors in the market has influenced idiosyncratic volatility. The stock market today is no longer a market of millions of individual investors whose buy and sell decisions are often likely to be uncoordinated. Today's market is dominated by institutions who get their news from the same sources, and who are often likely to change their sentiment simultaneously about both individual stocks and the market as a whole. ${ }^{17}$ volatility

The growing institutional presence in the stock market is apparent from Table 7. The percentage of total equity held by institutions has increased eight-fold from 1950 to 1998, and the proportion of block trades (trades of more than 10,000 shares, which are almost exclusively executed by institutional investors) has climbed to about half of total volume. Periodic surveys on the composition of traders on the New York Stock Exchange has indicated that on selected days as much as $90 \%$ of the trading has been generated by institutions (pension funds, mutual funds, etc.).

\section{Insert Table 7}

Turnover on the exchange has more than quadrupled since 1970. Moreover, when the 500 stocks in the $S \& P$ index were ranked by the percentage of institutional ownership as of December 1998, each of the 50 stocks in the top decile had $80 \%$ or more of their shares held by institutional investors. Institutional ownership for the median stock in the index was $62.5 \%$. Consequently, buying and selling is more likely to be coordinated across institutions, and market prices may be more volatile and more quickly responsive to new information or to changes in risk perceptions. While institutional trading can affect both market- and firm-level volatility, we suggest that institutional

\footnotetext{
${ }^{17}$ To the extent that individuals do still participate in trading, they tend to do so over the Internet and they tend to receive the same news simultaneously through electronic channels.
} 
trading will have far greater impact on individual volatility since the arrival of information on individual stocks is much more frequent. ${ }^{18}$

In order to investigate the role of institutions in influencing idiosyncratic volatility, we obtained panel data on institutional ownership for each stock in the $S \& P 500$ index portfolio during an eight year period from 1989 to 1996. We then examined if the degree of institutional ownership was related to the volatility of individual stocks by testing for a positive cross-sectional relationship during each of the eight years between the volatility of the stocks in the index and the percentage of institutional ownership.

Here idiosyncratic volatility is calculated as the mean of the squared residuals of daily returns over the fourth quarter of the year (which corresponds to the available institutional holding data) from the CAPM model fitted to each stock. ${ }^{19}$ Although the logarithmic transformation of volatilities in the OLS regression reduces much of the heteroscedasticity problem, residuals are still apparently positively skewed. Thus, usual statistical inference will be invalid (see McDonald and Newey, 1988). We estimated all the models using a partially adaptive estimator developed in McDonald and $\mathrm{Xu}(1995) .{ }^{20}$ Such an estimation technique not only nests the OLS method as a special case but also allows skewed and leptokurtic residuals. The first eight equations (Model I) in Table 8 show that, except for 1990, the logarithms of individual stocks' idiosyncratic volatilities are positively and significantly (at 5\% level or better) related to the proportion of institutional ownership. The result is strongest for 1995.

Volatility is also likely to be negatively correlated with the size of the company. Thus, our results may simply reflect a size effect. Therefore, we have also controlled

\footnotetext{
${ }^{18} \mathrm{~A}$ similar argument concerning coordinated trading may apply to individual investors engaged in "day trading" over the Internet who have tended to focus their trades on Internet-related companies.

${ }^{19}$ Since we are interested in the idiosyncratic volatility of individual stocks, this measure is used instead of the one suggested in Section 1. Furthermore, in order to obtain stable beta estimates, daily returns over the whole year are used in the estimation of the CAPM.

${ }^{20}$ Essentially, it is a maximum likelihood estimator based on the exponentially generalized beta distribution of type two (EGB2).
} 
for the size effect, where size is measured simply as the log of the total capitalized value of each firm. The eight equations of Model II in Table 8 suggest that the institutional ownership is still strongly related to the idiosyncratic volatilities even after controlling for the size effect.

\section{Insert Table 8}

In order to provide a summary statistic for our panel data, we have also run a pooling regression, where we pool all eight years of data together. As indicated in Table 8 , again we find strong evidence (now with zero $p$-values) that idiosyncratic volatility is positively related to institutional ownership after controlling for the size effect. The conclusion is further supported from evidence on pooled thirteen industry portfolios according to Ferson and Harvey's (1991) classification scheme shown in the last equation in Table 7. The $R^{2}$ for the regression is as high as $34 \%$. When the size variable is also included, the $R^{2}$ only increase to $38 \%$. In other words, it appears that the greater is the percentage of a firm's outstanding shares owned by institutions, the more volatile is the firm's stock returns relative to the market.

Gompers and Metrick (1999) find similar results between institutional ownership and total volatility. Of course, such a contemporaneous relationship does not reveal causality. Fortunately, we were able to investigate the direction of causality between ownership and idiosyncratic volatility in the sense of Granger causality. There are missing institutional ownership data in our sample. In other words, the number of stocks for which we have ownership data out of the 500 stocks ranges from 391 to 467 from 1989 to 1996. Furthermore, the $S \& P 500$ portfolio changes from year to year. In order to best use our sample, we constructed thirteen industry portfolios according to the SIC classification scheme used by Ferson and Harvey (1991) using value weighting. In particular, we estimated the following regression using the pooled industry portfolio 
data,

$$
\begin{aligned}
\log \left(V_{\text {idio. }, t}\right)= & -2.767+.391 \log \left(V_{\text {idio. }, t-1}\right)+.010 \text { Ownership } p_{t-1}+\hat{e}_{t} \quad R^{2}=0.481 \\
& (0.455)
\end{aligned}
$$

We rejected the hypothesis that the lagged institutional ownership variable has no explanatory power with an $F$ statistics of 14.08. This means that increases in institutional ownership Granger cause increases in the idiosyncratic volatility. Similarly, we can run the following regression,

$$
\begin{gathered}
\text { Ownership }_{t}= \\
(7.158) \\
(.042)
\end{gathered}
$$

However, we fail to reject the hypothesis that the lagged volatility variable has no explanatory power ( $F$ statistics of 2.93). In other words, Granger causality is not confirmed the other way around. Therefore, the evidence is consistent with our conjecture that the institutionalization of the market may have played a role in increasing the volatility of individual stocks. 


\section{$5 \quad$ Earning Growth and Idiosyncratic Volatility}

We further conjectured that companies who expect to enjoy high future growth rates are likely to exhibit high idiosyncratic volatility. Consider a company making a standard consumer product whose earnings may grow moderately with the growth of population but whose investments, if any, are likely to be very small, scale-changing investments. Thus, whatever investments are made are unlikely to involve new technologies. On the other hand, consider a high-growth company operating in an industry with rapid technological change, which is making substantial investments for future growth. Such a company is likely to face considerable technological change over time and, consequently, far greater risk. Indeed, from the firm's perspective, in order to keep up with the high growth expectations, the firm will need to reinvent itself from time to time by investing in unique projects. By definition, those unique projects will likely involve considerable idiosyncratic risk. Therefore, we believe that it is reasonable to expect that companies for which high expected growth is forecasted will also be likely to have high idiosyncratic volatility. We will test this hypothesis with cross- sectional regressions.

In order to classify companies in terms of their expected growth, we use the growth estimates of Wall Street security analysts who analyze corporations and their investment plans. Security analysts regularly publish long-run (specifically 5-year) growth estimates. These estimates are collected by IBES, the institutional brokerage estimate service.

The 1995 version of the IBES history tape on analysts' earnings projection is used in our empirical study. We examine the ten-year period from 1986 to 1995. In order to obtain reliable forecasts on earnings growth, we only include stocks that at least have two analysts making projections. For the same reason, wherever possible, we use 
the median of long-term forecasts on earnings growth. ${ }^{21}$ The idiosyncratic volatility for a particular firm is computed by estimating the mean square residuals from Fama and French's (1993) three factor model using monthly returns one year before and two years after the statistical date for any given year. ${ }^{22}$

In Table 9, we report the cross-sectional regressions of idiosyncratic volatility on expected long-term growth for each year from 1986 to 1995. The logarithm of volatility is used in actual regressions to reduce heteroscedasticity. It is evident that we can reject a hypothesis of no positive relationship between idiosyncratic volatility and expected growth rate at the $1 \%$ level or better. Moreover, $R^{2}$ s are moderate, ranging from $5 \%$ to $21 \%$. For example, in 1995, a $1 \%$ increase in earning growth corresponds to a percentage rise in the standard deviation of idiosyncratic risk. A pooling regression is also performed on the whole sample period. The estimates are very significant, with an $R^{2}$ of $11 \%$. As mentioned before, idiosyncratic volatility and firm size are highly correlated. In order to control for the size effect, we have also run multivariate crosssectional regressions. Although the corresponding estimates are somewhat smaller than before, they remain highly statistically significant. As expected, the $R^{2}$ s increase to more than $40 \%$.

\section{Insert Table 9}

It is also interesting to note that the relationship between idiosyncratic volatility and earning growth is nonlinear as shown in Figure 4, where size adjusted idiosyncratic volatility is used for 1995. It seems there is a turning point around a growth rate of $5 \%$. When the growth rate is above this point, a positive relationship between idiosyncratic volatility and growth rates is observed as we discussed above. However, there appears

\footnotetext{
${ }^{21}$ These are annualized earning growth rates for the next three or five years.

${ }^{22}$ The statistical date is the date when summary statistics are computed by IBES. Usually, the forecasts are made some time before the statistical date. Therefore, we use the three-year period to compute idiosyncratic volatility
} 
to be a negative relationship for firms with low growth or negative growth. Such patterns exist for every year except the first two years in our sample. This makes perfect sense. Firms with very low or negative growth are most likely to be in some degree of financial distress. Since the future of these firms is unclear, their stocks are likely to exhibit greater idiosyncratic volatility. This suggests that we may have much stronger results when the model is correctly specified.

\section{Insert Figure 4}

Applying a nonlinear least square technique, we have also estimated a "check shape" piecewise linear model. The results shown in Table 9 are highly significant with much steeper slope estimates than those from the simple OLS regressions. For example, in 1995, a $1 \%$ increase in earning growth is associated with a $1.33 \%$ increase in the standard deviation of idiosyncratic risk. The turning point is about $5 \%$. When we only use firms with growth rates that are higher than the turning point growth rate, which is estimated endogenously, the last two columns of Table 9 show very similar results with $R^{2}$ ranging from $13 \%$ to $29 \%$. Therefore, we conclude that the empirical evidence strongly supports our hypothesis. 


\section{Concluding Comments}

In this study, we have considered several plausible reasons why idiosyncratic volatility in the stock market should have increased over recent decades. The growth in the proportion of trading done by institutional investors may have increased the responsiveness of markets to changes in sentiment. Moreover, the focus on growth that dominated institutional investor preferences during the 1990s may have redirected firms' preferences in investment. By pursuing unique investment projects, firms are more vulnerable to idiosyncratic risk. We found cross-sectional evidence supporting an association between institutional ownership and the volatility of individual stocks as well as a positive relationship between idiosyncratic volatility and expected earning growth. Furthermore, the increasing prominence of NASDAQ market could also have contributed to high overall volatility. By extracting the NASDAQ stocks, we find a less dramatic idiosyncratic volatility trend, although it is still significant. However, high idiosyncratic volatility does not appear to be caused by the increase numbers of small stocks in our sample.

In this study, we have examined the similarities and differences in idiosyncratic volatility estimates using direct and indirect approaches. The persistence of volatility is very similar under both approaches. However, the indirect approach seems to overstate the overall level of idiosyncratic volatility. Moreover, the growth rate in idiosyncratic volatility tends to be higher using the indirect rather than the direct approach, although both are significant.

Finally, we find that the most volatile stocks each month (those with the largest percentage change in total return for the month) display an even more dramatic pattern of increasing volatility over time during the 25-year period from the late 1960s through the 1990s. This finding is not an artifact of some differential character of the most volatile stocks over time, such as a size effect. 


\section{Appendix}

In general, the excess return for each stock $R_{i, t}$ relative to the risk-free rate can be written as the sum of its systematic excess return component $R_{i, t}^{s}$, and its idiosyncratic return component $r_{i, t}$. Its corresponding volatility can also be decomposed into two components: systematic volatility and idiosyncratic volatility. Furthermore, we shall define the market portfolio as a value weighted portfolio of $N$ stocks, and its excess return will be defined as $R_{t}^{M}=\sum_{i=1}^{N} w_{i} R_{i, t}$, where the $w_{i}$ represents the weight of each stock in the index, with $\sum_{i=1}^{N} w_{i}=1$. In the case where the systematic element of a security's excess return, $R_{i, t}^{s}$, is simply the market excess return, $R_{t}^{M}$, we have the following relationship:

$$
\operatorname{Var}\left(R_{i, t}\right)=\operatorname{Var}\left(R_{t}^{M}\right)+\operatorname{Var}\left(r_{i, t}\right)+2 \operatorname{Cov}\left(R_{t}^{M}, r_{i, t}\right),
$$

and because by definition $\operatorname{Cov}\left(R_{t}^{M}, r_{i, t}\right)=0$, we obtain the following cross-sectional weighted sum,

$$
\sum_{i=1}^{N} w_{i} \operatorname{Var}\left(R_{i, t}\right)=\operatorname{Var}\left(R_{t}^{M}\right)+\sum_{i=1}^{N} w_{i} \operatorname{Var}\left(r_{i, t}\right) .
$$

Equation (14) suggests that the value-weighted aggregate volatility of individual stocks consists of the volatility imparted by movements in the broad market index and aggregate idiosyncratic volatility. While all the volatilities we have used are unconditional volatilities, under the common information assumption, the decomposition in equation (14) also holds for conditional variances. This equation provides a simple and feasible approach to calculate conditional aggregate idiosyncratic volatility as in equation (15), and is restated in the following,

$$
\hat{v}_{I, t}^{2}=\hat{v}_{A, t}^{2}-\hat{v}_{M, t}^{2}
$$

Under the previous assumptions, equation (15) is an exact relationship. Therefore, aggregate idiosyncratic volatility can be correctly estimated as long as $\hat{v}_{A, t}^{2}$ and $\hat{v}_{M, t}^{2}$ 
are unbiased. The decomposition is not exact for more complex models of systematic return but is a good approximation for the cases considered. For example, in the case where the systematic excess return $R_{i, t}^{s}$ is a function of the market excess return $R_{t}^{M}$, the Capital Asset Pricing Model (CAPM) holds. The systematic excess return can then be expressed as $\beta_{i} R_{t}^{M}$. Similar to equation (13), we have the following,

$$
\operatorname{Var}\left(R_{i, t}\right)=\beta_{i}^{2} \operatorname{Var}\left(R_{t}^{M}\right)+\operatorname{Var}\left(r_{i, t}\right)+2 \beta_{i} \operatorname{Cov}\left(R_{t}^{M}, r_{i, t}\right)
$$

Taking weighted sums across individual stocks yields:

$$
\sum_{i=1}^{N} w_{i} \operatorname{Var}\left(R_{i, t}\right)=\hat{\beta}^{2} \operatorname{Var}\left(R_{t}^{M}\right)+\sum_{i=1}^{N} w_{i} \operatorname{Var}\left(r_{i, t}\right),
$$

where $\hat{\beta}^{2}=\sum_{i=1}^{N} w_{i} \beta_{i}^{2}$. Here again one can replace unconditional second moments by conditional ones if the common information restriction holds. However, as Campbell (1991) has shown, past interest rates may help to predict $R^{M}$ and we do not take such a relationship into account in the computation of conditional variances. Because the predictability is weak, however, the problem of incorrect use of univariate information sets is likely to be small.

When we use equation (15) to estimate aggregate idiosyncratic volatility, $v_{I, t}$, the volatility estimate will be biased by $\left(\hat{\beta}^{2}-1\right) v_{M, t}^{2}$. If, as an approximation, we treat the weights $w_{i}$ as some probability measure, then $\hat{\beta}^{2}-1$ is the variance of $\beta_{i}$. In this case, the volatility measure will be biased upwards. However, the estimated bias is likely to be small, in the neighborhood of $4 \%$ to $5 \%$ of the market volatility. ${ }^{23}$ Furthermore, if the market volatility is stable, as we shall show it is, the bias will have little effect on the magnitude of the trend over time since all the volatility estimates will suffer the same degree of bias. Moreover, the empirical evidence of little correlation between $\hat{v}_{I, t}^{2}$ and $v_{M, t}^{2}$ also suggests that the bias is likely to be quite small. ${ }^{24}$

\footnotetext{
${ }^{23}$ These bias estimates are based on the construction of 100 portfolios of the type used by Fama and French (1992) over our sample period.

${ }^{24}$ Schwert and Seguin (1990) have shown that the cross-sectional dispersion in betas is correlated
} 


\section{References}

[1] Andersen, T.G.; Bollerslev, T.; Diebold, F.X.; and Ebens, H. 2001. The distribution of realized stock return volatility. Journal of Financial Economics 61: 43-76.

[2] Andersen, T.G.; Bollerslev, T. 1997. Intraday periodicity and volatility persistence in financial markets. Journal of Empirical Finance 4: 115-158.

[3] Bollerslev, T.; Chou, R.Y.; and Kroner, K.F. 1992. ARCH modeling in finance: a review of the theory and empirical Evidence. Journal of Econometrics 52: 5-59.

[4] Bollerslev, T.; Engle, R.F.; and Nelson, D.B. 1994. ARCH models, in Handbook of Econometrics. Vol. 4 (R.F. Engle and D. McFadden, eds.), Amsterdam: North Holland Press.

[5] Braun, P.A.; Nelson, D.B.; and Sunier, A.M. 1995. Good news, bad news, volatility, and beta. Journal of Finance 50: 1575-1603.

[6] Campbell, J. Y. 1991. A variance decomposition for stock returns. The Economic Journal 101 (405): 157-79.

[7] Campbell, J. Y.; Lettau, M.; Malkiel, B.G. and Xu, Y. 2001. Have individual stocks become more volatile? an empirical exploration of idiosyncratic risk. The Journal of Finance 56: 1-43.

[8] Canjels, E., and Watson, M. W. 1997. Estimating deterministic trends in the presence of serially correlated errors. The Review of Economics and Statistics 79: 184-200.

with the level of market volatility. This conclusion is reached by comparing an equally weighted group of small-stock portfolios with an equally weighted group of large-stock portfolios. In order to account for this effect, we have used value weighting in this study since large dispersion in betas is much more significant for small stocks than for large stocks. 
[9] Chou, R.Y. 1988. Volatility persistence and stock valuations. Journal of Applied Econometrics 3: 279-294.

[10] Engle, R.F. 2001. The econometrics of ultra-high- frequency data. Econometrica 68: $1-22$.

[11] Engle, R.F., and Russell, J.R. 1997. Forecasting the frequency of changes in quoted foreign exchange prices with the autoregressive conditional duration model. Journal of Empirical Finance 4: 187-212.

[12] Engle, R.F., and Russell, J.R. 1998. Autoregressive conditional duration: a new model for irregularly spaced transaction data. Econometrica 66: 1127-1162.

[13] Fama, E.F., and French, K. R. 1988. Permanent and temporary components of stock prices. Journal of Political Economy 96 (April): 246-73.

[14] 1992. The cross-section of expected stock returns. Journal of Finance 47: 427- 465 .

[15] _ 1993. Common risk factors in the returns on stocks and bonds. Journal of Financial Economics 33: 3-56.

[16] Ferson, W.E., and Harvey, C.R. 1991. The variation of economic risk premiums. Journal of Political Economy 99: 385-415.

[17] French, K.R.; Schwert, G.W.; and Stambaugh, R.F. 1987. Expected stock returns and volatility. Journal of Financial Economics 19: 3-29.

[18] Foster, D.P., and Nelson, D.B. 1996. Continuous record asymptotics for rolling sample variance estimators. Econometrica 64: 139-174.

[19] Ghysels, E.; Harvey, A.; and Renault, E. 1997. Stochastic volatility, in Handbook of Statistics, Vol. 14 (G.S. Maddala, eds.), Amsterdam: North Holland Press. 
[20] Ghysels, E., and Perron, P. 1993. The effect of seasonal adjustment filters on tests for a unit root. Journal of Econometrics 55: 57-98.

[21] Gompers, P.A., and Metrick, A. 2001. Institutional investors and equity prices. Quarterly Journal of Economics 116: 229-59.

[22] Hasbrouck, J. 1999. The dynamics of discrete bid and ask quotes. Journal of Finance 54: 2109-2142.

[23] Ibbotson Associates 1998. Stocks, Bonds, Bills, and Inflation: 1998 Yearbook, Chicago.

[24] Lys, T., and Sabino, J.S. 1992. Research design issues in grouping-based tests. Journal of Financial Economics 32: 355-387.

[25] Malkiel, B.G., and Xu, Y. 2000. Idiosyncratic risk and security returns. Working Paper, School of Management, The University of Texas at Dallas.

[26] Malkiel, B.G., and Xu, Y. 1997. Risk and return revisited. Journal of Portfolio Management 23 (3): 9-14.

[27] McDonald, J.B., and Newey, W.K. 1988. Partially ddaptive estimation of regression models via the generalized t- distribution. Econometric Theory 4: 428-457.

[28] McDonald, J.B., and Xu, Y. 1995 A generalization of the beta distribution with applications. Journal of Econometrics 66: 133-152.

[29] Schwert, G.W. 1989. Why does stock market volatility change over time?' Journal of Finance 44: 1115-1153.

[30] Schwert, G.W., and Seguin, P.J. 1990 Heteroskedasticity in stock returns. Journal of Finance 45: 1129-55. 
[31] Vogelsang, T. 1998. Trend function hypothesis testing in the presence of serial correlation. Econometrica 66: 123-148. 
Table 1: Simulation Results for Window Lengths and Decay Rates

This table shows the results of simulations used to determine window lengths and decay rates. Rolling regressions with different weighting schemes are used to estimate volatility on return data generated according to equations (6) and (7). These volatility estimates are then fitted to the following model using the GLS procedure described in Section 1.2,

$$
v_{t}=\kappa+\gamma t+\theta v_{t-1}+\epsilon_{t} .
$$

\begin{tabular}{|c|c|c|c|c|c|c|c|c|c|c|c|c|c|c|}
\hline \multirow{2}{*}{$\begin{array}{l}\text { True } \\
\text { Param. }\end{array}$} & \multirow[b]{2}{*}{ C.I. } & \multirow{2}{*}{$\begin{array}{c}\text { GARCH } \\
\text { Volt. } \\
\end{array}$} & \multicolumn{4}{|c|}{ Type I Weights w/ 12 Lags } & \multicolumn{4}{|c|}{ Type I Weights w/ 24 Lags } & \multicolumn{4}{|c|}{ Type II Weights } \\
\hline & & & $.8^{k}$ & $.85^{k}$ & $.9^{k}$ & $.95^{k}$ & $.8^{k}$ & $.85^{k}$ & $.9^{k}$ & $.95^{k}$ & 6lags & 12lags & 18lags & 24lags \\
\hline & & \multicolumn{13}{|c|}{$\hat{\gamma}$ Estimates } \\
\hline$\kappa=2.592$ & Up90 & 2.89 & 2.54 & 2.05 & 1.66 & 1.36 & 2.45 & 1.88 & 1.33 & .848 & 3.99 & 1.92 & 1.33 & 1.02 \\
\hline$\gamma=2.000$ & Mode & 2.12 & 1.67 & 1.33 & 1.06 & .866 & 1.61 & 1.21 & .821 & .493 & 2.41 & 1.24 & .822 & .606 \\
\hline$\theta=.8519$ & Lw10 & 1.53 & .932 & .758 & .589 & .475 & .926 & .691 & .449 & .253 & 1.17 & .705 & .448 & .322 \\
\hline$\kappa=2.178$ & Up90 & 3.02 & 2.89 & 2.34 & 1.88 & 1.53 & 2.78 & 2.13 & 1.49 & .939 & 4.61 & 2.19 & 1.48 & 1.14 \\
\hline$\gamma=2.000$ & Mode & 2.16 & 1.89 & 1.51 & 1.20 & .975 & 1.83 & 1.36 & .914 & .542 & 2.79 & 1.41 & .914 & .670 \\
\hline$\theta=.8756$ & Lw10 & 1.50 & 1.08 & .861 & .671 & .535 & 1.05 & .775 & .497 & .277 & 1.40 & .800 & .499 & .352 \\
\hline$\kappa=1.763$ & Up90 & 3.19 & 3.39 & 2.75 & 2.20 & 1.78 & 3.26 & 2.48 & 1.70 & 1.06 & 5.43 & 2.57 & 1.70 & 1.30 \\
\hline$\gamma=2.000$ & Mode & 2.20 & 2.21 & 1.76 & 1.39 & 1.12 & 2.12 & 1.56 & 1.03 & .607 & 3.34 & 1.63 & 1.04 & .753 \\
\hline$\theta=.8993$ & Lw10 & 1.47 & 1.27 & .999 & .783 & .613 & 1.22 & .883 & .557 & .309 & 1.70 & .928 & .563 & .392 \\
\hline$\kappa=1.349$ & Up90 & 3.42 & 4.13 & 3.36 & 2.69 & 2.16 & 3.97 & 2.98 & 2.03 & 1.26 & 6.73 & 3.12 & 2.02 & 1.53 \\
\hline$\gamma=2.000$ & Mode & 2.26 & 2.69 & 2.13 & 1.66 & 1.34 & 2.55 & 1.85 & 1.20 & .697 & 4.18 & 1.97 & 1.22 & .868 \\
\hline$\theta=.9229$ & Lw10 & 1.43 & 1.52 & 1.19 & .920 & .724 & 1.46 & 1.03 & .637 & .340 & 2.16 & 1.10 & .654 & 443 \\
\hline$\kappa=.9348$ & Up90 & 3.83 & 5.46 & 4.41 & 3.49 & 2.80 & 5.19 & 3.86 & 2.61 & 1.58 & 8.92 & 4.08 & 2.62 & 1.91 \\
\hline$\gamma=2.000$ & Mode & 2.39 & 3.50 & 2.74 & 2.13 & 1.70 & 3.26 & 2.33 & 1.48 & .838 & 5.64 & 2.53 & 1.51 & 1.05 \\
\hline$\theta=.9466$ & Lw10 & 1.36 & 1.95 & 1.48 & 1.13 & .900 & 1.81 & 1.25 & .746 & .385 & 2.89 & 1.36 & .779 & .507 \\
\hline$\kappa=.5205$ & Up90 & 4.76 & 8.26 & 6.56 & 5.16 & 4.16 & 7.76 & 5.65 & 3.70 & 2.19 & 13.9 & 6.08 & 3.81 & 2.72 \\
\hline$\gamma=2.000$ & Mode & 2.69 & 5.17 & 3.98 & 3.04 & 2.42 & 4.74 & 3.29 & 2.03 & 1.12 & 8.70 & 3.66 & 2.10 & 1.41 \\
\hline \multirow[t]{2}{*}{$\theta=.9703$} & Lw10 & 1.32 & 2.72 & 2.05 & 1.55 & 1.21 & 2.48 & 1.64 & .942 & .452 & 4.39 & 1.88 & 1.00 & .612 \\
\hline & & \multicolumn{13}{|c|}{$\hat{\theta}$ Estimates } \\
\hline$\kappa=2.592$ & Up90 & .884 & .898 & .921 & .939 & .952 & .904 & .932 & .957 & .976 & .837 & .927 & .956 & .970 \\
\hline$\gamma=2.000$ & Mode & .841 & .857 & .887 & .912 & .929 & .863 & .899 & .933 & .961 & .769 & .895 & .933 & .951 \\
\hline$\theta=.8519$ & Lw10 & .786 & .803 & .842 & .874 & .897 & .811 & .857 & .901 & .937 & .679 & .852 & .901 & .924 \\
\hline$\kappa=2.178$ & Up90 & .904 & .904 & .926 & .943 & .955 & .910 & .937 & .961 & .978 & .843 & .932 & .960 & .973 \\
\hline$\gamma=2.000$ & Mode & .863 & .862 & .892 & .916 & .932 & .869 & .905 & .938 & .963 & .776 & .900 & .937 & .954 \\
\hline$\theta=.8756$ & Lw10 & .813 & .809 & .847 & .878 & .901 & .818 & .862 & .905 & .941 & .684 & .858 & .906 & .928 \\
\hline$\kappa=1.763$ & Up90 & .925 & .912 & .932 & .948 & .959 & .917 & .943 & .965 & .981 & .850 & .938 & .964 & .976 \\
\hline$\gamma=2.000$ & Mode & .886 & .869 & .898 & .921 & .937 & .876 & .911 & .942 & .967 & .782 & .906 & .942 & .958 \\
\hline$\theta=.8993$ & Lw10 & .839 & .815 & .852 & .883 & .906 & .825 & .868 & .911 & .945 & .689 & .863 & .910 & .933 \\
\hline$\kappa=1.349$ & Up90 & .945 & .920 & .940 & .954 & .964 & .926 & .950 & .970 & .984 & .860 & .945 & .969 & .980 \\
\hline$\gamma=2.000$ & Mode & .910 & .877 & .905 & .926 & .941 & .885 & .918 & .948 & .970 & .791 & .912 & .947 & .963 \\
\hline$\theta=.9229$ & Lw10 & .865 & .823 & .859 & .889 & .912 & .832 & .876 & .917 & .950 & .697 & .869 & .916 & .938 \\
\hline$\kappa=.9348$ & Up90 & .963 & .932 & .948 & .961 & .970 & .937 & .959 & .976 & .989 & 8.873 & .953 & .974 & .984 \\
\hline$\gamma=2.000$ & Mode & .933 & .888 & .913 & .934 & .948 & .896 & .927 & .955 & .975 & .803 & .921 & .954 & .968 \\
\hline$\theta=.9466$ & Lw10 & .892 & .832 & .868 & .898 & .918 & .842 & .884 & .924 & .955 & .708 & .878 & .923 & .944 \\
\hline$\kappa=.5205$ & Up90 & .980 & .947 & .961 & .972 & .979 & .953 & .971 & .984 & .994 & .893 & .965 & .983 & .990 \\
\hline$\gamma=2.000$ & Mode & .956 & .902 & .926 & .944 & .956 & .911 & .940 & .964 & .981 & .820 & .932 & .962 & .975 \\
\hline$\theta=.9703$ & Lw10 & .922 & .844 & .879 & .906 & .926 & .855 & .896 & .934 & .962 & .725 & .888 & .932 & .952 \\
\hline
\end{tabular}


Table 2: Critical Values of a GLS Estimator of Volatility Trend

This table shows the critical values of a $t$ type test on a GLS estimator of volatility trend described in Section 1.2. The volatilities are estimated using rolling regressions with selected weighting schemes.

\begin{tabular}{|c|c|c|c|c|c|c|c|c|}
\hline \multirow{2}{*}{$\begin{array}{l}\text { True } \\
\theta\end{array}$} & \multicolumn{8}{|c|}{ Critical Value for $\gamma$} \\
\hline & 99.5 & 99.0 & 97.5 & 95.0 & 5.0 & 2.5 & 1.0 & 0.5 \\
\hline & \multicolumn{8}{|c|}{ Using Type I Weights $\left(.85^{k}\right)$ Over 24 Lags } \\
\hline 0.85194 & $\overline{9}$ & 5 & 2.0491 & 1.7372 & -1.7196 & -2.0316 & -2.4864 & 2.8260 \\
\hline 0.8 & 561 & 2.3268 & 2.0562 & 1.7487 & -1.7331 & -2.0532 & -2.4674 & -2.8401 \\
\hline 9927 & 969 & 3410 & 2.0887 & 1.7757 & -1.7559 & -2.0654 & -2.4796 & -2.9592 \\
\hline 0.92293 & 6483 & 2.3883 & 2.1353 & 1.8307 & -1.8280 & -2.1037 & -2.5449 & -3.0367 \\
\hline 0.94 & 6927 & 5184 & 2.2346 & 1.9183 & -1.9414 & -2.2363 & -2.6589 & -3.1605 \\
\hline \multirow[t]{2}{*}{0.97026} & 881 & 7778 & 2.4553 & 2.0425 & -2.1008 & -2.4664 & -2.9495 & -3.2086 \\
\hline & \multicolumn{8}{|c|}{ Using Type I Weights $\left(.90^{k}\right)$ Over 24 Lags } \\
\hline & 1 & & 1.9225 & 1.6082 & $\begin{array}{l}-1.5982 \\
\end{array}$ & -1.8682 & $\begin{array}{l}-2.3272 \\
\end{array}$ & $\begin{array}{l}-2.7470 \\
\end{array}$ \\
\hline & 6 & 15 & & & & -1.8800 & -2.3029 & -2.7126 \\
\hline & 281 & 687 & & & & -1.8997 & 685 & -2.6749 \\
\hline 293 & 4404 & 1906 & & & & -1.9253 & -2.3039 & -2.6340 \\
\hline 0 & 4910 & .2595 & 2.0085 & & & -1.9714 & -2.3947 & -2.6117 \\
\hline \multirow[t]{2}{*}{0.97026} & 6630 & 2.4294 & 2.1682 & 1.8045 & -1.8464 & -2.1313 & -2.5162 & -2.7224 \\
\hline & \multicolumn{8}{|c|}{ Using Type II Weights $\left(e^{-\alpha k}\right)$ Over 12 Lags } \\
\hline 0.85194 & 4808 & 3814 & 1.9664 & 1.6293 & -1.7274 & -1.9605 & -2.4676 & -2.7844 \\
\hline & 2.5239 & 8 & 1.9 & & & 61 & -2 & -2.8277 \\
\hline 0.89927 & 2.5976 & 2.4571 & 2.0362 & & & -2.0530 & -2.4999 & -2.8947 \\
\hline 0.92293 & 2.7271 & 2.5182 & 2.1418 & & -1 . & -2.1519 & -2.5747 & -3.0023 \\
\hline 0.94660 & 2.9674 & 2.6159 & 2.2285 & & -1.9 & -2.2896 & -2.7529 & -3.2339 \\
\hline \multirow[t]{2}{*}{0.97026} & 1743 & 8581 & 2.5169 & 2.1154 & -2.2183 & -2.5785 & -2.9718 & -3.4088 \\
\hline & \multicolumn{8}{|c|}{ Using Type II Weights $\left(e^{-\alpha k}\right)$ Over 18 Lags } \\
\hline 0.85194 & 2804 & 2.1670 & 1.8559 & 1.5640 & -1.5435 & -1.8372 & -2.2871 & $\begin{array}{l}-2.6206 \\
\end{array}$ \\
\hline 561 & 2997 & 2.1485 & 1.8744 & 1.5 & -1.5 & -1.8412 & -2.2606 & -2.6711 \\
\hline & 2.3061 & 2.1445 & 1.9042 & & -1.5705 & -1.8606 & -2.2442 & -2.6994 \\
\hline 3 & 2.3152 & 2.1593 & 1.9377 & 1.6 & -1.6016 & -1.9030 & -2.2579 & -2.6740 \\
\hline & 2.4853 & 2.2447 & 1.9954 & & -1.6 & -1.9691 & -2.3519 & -2.6556 \\
\hline 0.97026 & 2.7139 & 2.4221 & 2.1460 & 1.8072 & -1.8647 & -2.1292 & -2.5546 & -2.7448 \\
\hline
\end{tabular}


Table 3: Average Volatilities over Different Decade

This table shows the average of different measures of volatility for the '50s, '60s, '70s, ' $80 \mathrm{~s}$, and '90s. The volatilities for the most volatile stocks are calculated from daily returns, while other volatilities are computed using rolling estimates discussed in Section 1.2. Note that the '60s denotes the period from 1963 to 1969 for the most volatile stocks; the '70s denotes the period from 1975 to 1979 in the NASDAQ sample; and the '90s denotes the period from 1990 to 1998. "Idio I" is the idiosyncratic volatility constructed by subtracting index volatility from the corresponding aggregate total volatility, while "Idio II" is the idiosyncratic volatility calculated directly from the Fama and French (1993) three factor model.

\begin{tabular}{|c|c|c|c|c|c|c|c|c|c|c|}
\hline & $50 \mathrm{~s}$ & $60 \mathrm{~s}$ & $70 \mathrm{~s}$ & $80 \mathrm{~s}$ & $90 \mathrm{~s}$ & $50 \mathrm{~s}$ & $60 \mathrm{~s}$ & $70 \mathrm{~s}$ & $80 \mathrm{~s}$ & $90 \mathrm{~s}$ \\
\hline & \multicolumn{10}{|c|}{ Panel A: The most volatile stocks } \\
\hline Market & & 0.48 & 0.75 & 0.82 & 0.70 & & & & & \\
\hline Top20 & & 10.6 & 13.2 & 19.4 & 28.2 & & & & & \\
\hline Top50 & & 8.63 & 11.1 & 16.1 & 24.3 & & & & & \\
\hline Top10p & & 5.70 & 6.47 & 8.00 & 11.4 & & & & & \\
\hline \multirow[t]{3}{*}{ Top $27 \mathrm{p}$} & & 4.25 & 4.86 & 5.75 & 8.09 & & & & & \\
\hline & \multicolumn{5}{|c|}{ using power weights } & \multicolumn{5}{|c|}{ using exponential weights } \\
\hline & \multicolumn{10}{|c|}{ Panel B: NYSE/AMEX/NASDAQ sample } \\
\hline Market & 3.05 & 3.24 & 4.28 & 4.47 & 3.30 & 2.95 & 3.17 & 4.19 & 4.33 & 3.25 \\
\hline Total & 5.62 & 6.31 & 7.99 & 8.65 & 8.00 & 5.55 & 6.23 & 7.89 & 8.53 & 7.93 \\
\hline Idio I & 4.70 & 5.35 & 6.71 & 7.34 & 7.22 & 4.66 & 5.28 & 6.64 & 7.27 & 7.16 \\
\hline \multirow[t]{2}{*}{ Idio II } & 4.20 & 4.84 & 5.99 & 6.65 & 6.56 & 4.17 & 4.78 & 5.93 & 6.59 & 6.50 \\
\hline & \multicolumn{10}{|c|}{ Panel C: $S \& P$ 500 sample } \\
\hline Market & 2.96 & 3.08 & 4.01 & 4.23 & 3.23 & 3.05 & 3.15 & 4.10 & 4.35 & 3.28 \\
\hline Total & 5.41 & 5.78 & 7.19 & 7.79 & 6.87 & 5.48 & 5.86 & 7.29 & 7.88 & 6.91 \\
\hline Idio I & 4.49 & 4.82 & 5.91 & 6.44 & 5.98 & 4.52 & 4.88 & 5.98 & 6.50 & 6.02 \\
\hline \multirow[t]{2}{*}{ Idio II } & 4.02 & 4.40 & 5.35 & 5.87 & 5.42 & 4.05 & 4.44 & 5.41 & 5.92 & 5.46 \\
\hline & \multicolumn{10}{|c|}{ Panel D: NYSE/AMEX sample } \\
\hline Market & 3.05 & 3.24 & 4.36 & 4.49 & 3.19 & 2.95 & 3.17 & 4.27 & 4.35 & 3.15 \\
\hline Total & 5.62 & 6.31 & 7.86 & 8.24 & 7.18 & 5.55 & 6.23 & 7.75 & 8.12 & 7.13 \\
\hline Idio I & 4.70 & 5.35 & 6.49 & 6.84 & 6.38 & 4.66 & 5.28 & 6.42 & 6.78 & 6.33 \\
\hline \multirow[t]{2}{*}{ Idio II } & 4.20 & 4.84 & 5.75 & 6.18 & 5.81 & 4.17 & 4.78 & 5.69 & 6.13 & 5.77 \\
\hline & \multicolumn{10}{|c|}{ Panel E: NASDAQ sample } \\
\hline Market & & & 4.82 & 5.43 & 4.59 & & & 4.94 & 5.60 & 4.64 \\
\hline Total & & & 9.06 & 10.8 & 11.8 & & & 9.25 & 10.9 & 12.0 \\
\hline Idio I & & & 7.62 & 9.21 & 10.8 & & & 7.77 & 9.29 & 10.9 \\
\hline Idio II & & & 7.79 & 8.98 & 10.0 & & & 7.93 & 9.07 & 10.1 \\
\hline
\end{tabular}


Table 4: Test Statistics for the Most Volatile Stocks from the NYSE/AMEX/NASDAQ Markets

This table shows that the volatility of the most volatile stocks has increased over time. The $t$ type tests are based on the GLS estimate of the following model,

$$
V_{t}=\mu+\theta V_{t-1}+\gamma t+\alpha_{1} \Delta V_{t-1}+\cdots+\alpha_{p} \Delta V_{t-p}+\epsilon_{t} .
$$

Twelve lags are used according to AIC and BIC criteria. The critical values on $\hat{\gamma}$ estimates can be found in Table 3. The robust Wald type tests of Vogelsang are based on estimates from equation (17) in Section 1.4 using $\log$ volatility. Therefore, $\hat{\gamma}$ is the growth rate of volatility. The corresponding $90 \%$ confidence intervals for $\hat{\gamma}$ are reported here for convenience.

\begin{tabular}{|c|c|c|c|c|c|c|c|c|c|}
\hline & \multicolumn{4}{|c|}{20 Most Volatile Stocks } & \multicolumn{4}{|c|}{50 Most Volatile Stocks } \\
\hline & & $\mu$ & $\theta$ & $\gamma$ & $R^{2}$ & $\mu$ & $\theta$ & $\bar{\gamma}$ & $R^{2}$ \\
\hline \multirow{2}{*}{\multicolumn{2}{|c|}{$\begin{array}{l}V_{t} \\
t \text {-Value }\end{array}$}} & .0052 & 0.923 & .000047 & 0.821 & .0038 & 0.931 & .000037 & 0.858 \\
\hline & & 2.244 & 32.96 & 2.907 & & 2.221 & 36.47 & 2.908 & \\
\hline \multirow{5}{*}{$\begin{array}{l}90 \% \\
\text { Confidence } \\
\text { Interval } \\
\end{array}$} & $\hat{\gamma}_{\min }$ & & & .00225 & & & & .00242 & \\
\hline & & & & .00312 & & & & .00321 & \\
\hline & $\hat{\gamma}_{\max }$ & & & .00400 & & & & .00401 & \\
\hline & & & Most & olatile S & & & $\overline{\text { Most }}$ & latile St & cks \\
\hline & & $\mu$ & $\theta$ & $\gamma$ & $R^{2}$ & $\mu$ & $\theta$ & $\gamma$ & $R^{2}$ \\
\hline \multirow{2}{*}{\multicolumn{2}{|c|}{$\begin{array}{l}V_{t} \\
t \text {-Value }\end{array}$}} & .0038 & 0.915 & .000015 & 0.755 & .0036 & 0.900 & .000011 & 0.685 \\
\hline & & 2.668 & 31.33 & 2.890 & & 2.795 & 26.46 & 2.836 & \\
\hline $90 \%$ & $\hat{\gamma}_{\min }$ & & & .00121 & & & & .00106 & \\
\hline Confidence & $\hat{\gamma}$ & & & .00198 & & & & .00174 & \\
\hline Interval & $\hat{\gamma}_{\max }$ & & & .00275 & & & & .00243 & \\
\hline
\end{tabular}


Table 5: Test Statistics for NYSE/AMEX/NASDAQ Index Portfolio

This table presents tests rejecting the existence of time trends in the volatility of the indices, and failing to reject time trends in the aggregated idiosyncratic volatility series. The $t$ type tests are based on the GLS estimates of the following model,

$$
V_{t}=\mu+\theta V_{t-1}+\gamma t+\alpha_{1} \Delta V_{t-1}+\cdots+\alpha_{p} \Delta V_{t-p}+\epsilon_{t}
$$

where the $V_{t}$ series are standard deviations. Six lags are used according to AIC and BIC criteria. The critical value on $\hat{\gamma}$ estimates can be found in Table 1. The robust Wald type tests of Vogelsang are based on estimates from equation (9) in Section 1.2 using $\log$ volatility. Therefore, $\hat{\gamma}$ is the growth rate of volatility. The corresponding $90 \%$ confidence intervals for $\hat{\gamma}$ are reported here for convenience. "Idiosyncratic Volatility I" is constructed by subtracting index volatility from the corresponding aggregate total volatility, while "Idiosyncratic Volatility II" is calculated directly from the Fama and French (1993) three factor model.

\begin{tabular}{|c|c|c|c|c|c|c|c|c|c|}
\hline & \multicolumn{4}{|c|}{$\begin{array}{c}\text { Type I Geometric Weights }\left(.9^{k}\right) \\
\text { with Window Length of } 24\end{array}$} & \multicolumn{4}{|c|}{$\begin{array}{c}\text { Type II Geometric Weights }\left(e^{-\alpha k}\right) \\
\text { with Window Length of } 12\end{array}$} \\
\hline & & $\mu$ & $\theta$ & $\gamma \times 10^{-4}$ & $R^{2}$ & $\bar{\mu}$ & $\theta$ & $\gamma \times 10^{-4}$ & $R^{2}$ \\
\hline & & \multicolumn{8}{|c|}{ Index Volatility } \\
\hline \multirow{2}{*}{\multicolumn{2}{|c|}{$\begin{array}{l}V_{t} \\
t \text {-Value }\end{array}$}} & .0024 & 0.929 & .0111 & \multirow[t]{2}{*}{0.517} & .0026 & 0.920 & .0136 & \multirow[t]{2}{*}{0.492} \\
\hline & & 3.198 & 46.9 & 0.920 & & 3.386 & 44.70 & 1.020 & \\
\hline $90 \%$ & $\hat{\gamma}_{\min }$ & \multirow{2}{*}{\multicolumn{4}{|c|}{$\begin{array}{r}-.00069 \\
00071\end{array}$}} & \multicolumn{4}{|c|}{-.00061} \\
\hline Confidence & & \multirow{2}{*}{\multicolumn{3}{|c|}{$\begin{array}{l}.00071 \\
00212\end{array}$}} & & \multicolumn{4}{|c|}{.00072} \\
\hline Interval & $\hat{\gamma}_{\max }$ & & & .00212 & & & & .00204 & \\
\hline \multirow{2}{*}{\multicolumn{2}{|c|}{$V_{t}$}} & \multicolumn{8}{|c|}{ Aggregate Volatility } \\
\hline & & .0029 & 0.949 & .0354 & 0.805 & .0032 & 0.942 & .0398 & 0.782 \\
\hline \multicolumn{2}{|l|}{$t$-Value } & 3.367 & 64.83 & 2.758 & & 3.631 & 61.30 & 2.899 & \\
\hline $90 \%$ & $\hat{\gamma}_{\min }$ & \multicolumn{4}{|c|}{.00021} & \multicolumn{4}{|c|}{.00025} \\
\hline Confidence & & \multicolumn{4}{|c|}{.00108} & \multicolumn{4}{|c|}{.00108} \\
\hline \multirow[t]{2}{*}{ Interval } & $\hat{\gamma}_{\max }$ & \multicolumn{4}{|c|}{.00196} & \multicolumn{4}{|c|}{.00191} \\
\hline & & \multicolumn{8}{|c|}{ Idiosyncratic Volatility I } \\
\hline \multirow{2}{*}{\multicolumn{2}{|c|}{$\begin{array}{l}V_{t} \\
t \text {-Value }\end{array}$}} & .0017 & 0.962 & .0258 & \multirow[t]{2}{*}{0.915} & .0019 & 0.958 & .0281 & \multirow[t]{2}{*}{0.907} \\
\hline & & 3.337 & 88.20 & 3.071 & & 3.618 & 85.97 & 3.249 & \\
\hline $90 \%$ & $\hat{\gamma}_{\min }$ & \multirow{2}{*}{\multicolumn{4}{|c|}{$\begin{array}{l}.00033 \\
00120\end{array}$}} & \multicolumn{4}{|c|}{.00036} \\
\hline Confidence & & & & & & & & .00120 & \\
\hline \multirow[t]{2}{*}{ Interval } & $\hat{\gamma}_{\max }$ & \multicolumn{4}{|c|}{.00208} & \multicolumn{4}{|c|}{.00205} \\
\hline & & \multicolumn{8}{|c|}{ Idiosyncratic Volatility II } \\
\hline$V_{t}$ & & .0013 & 0.968 & .0201 & 0.940 & .0014 & 0.964 & .0222 & 0.932 \\
\hline$t$-Value & & 3.094 & 96.15 & 2.979 & & 3.341 & 91.83 & 3.156 & \\
\hline $90 \%$ & $\hat{\gamma}_{\text {min }}$ & & & .00030 & & & & .00034 & \\
\hline Confidence & $\hat{\gamma}$ & & & .00121 & & & & .00121 & \\
\hline Interval & $\hat{\gamma}_{\max }$ & & & .00211 & & & & .00207 & \\
\hline
\end{tabular}


Table 6: Test Statistics for the Simulated $S \& P 500$ Index Portfolio, NYSE/AMEX Index Portfolio and NASDAQ Index Portfolio

This table presents tests rejecting the existence of time trends in the volatility of the indices, and failing to reject time trends in the aggregated idiosyncratic volatility series. The $t$ type tests are based on the GLS estimates of the following model,

$$
V_{t}=\mu+\theta V_{t-1}+\gamma t+\alpha_{1} \Delta V_{t-1}+\cdots+\alpha_{p} \Delta V_{t-p}+\epsilon_{t}
$$

where the $V_{t}$ series are standard deviations. Six lags are used according to AIC and BIC criteria. The critical value on $\hat{\gamma}$ estimates can be found in Table 1 . The robust Wald type tests of Vogelsang are based on estimates from equation (9) in Section 1.2 using $\log$ volatility. Therefore, $\hat{\gamma}$ is the growth rate of volatility. The corresponding $90 \%$ confidence intervals for $\hat{\gamma}$ are reported here for convenience. "Idiosyncratic Volatility I" is constructed by subtracting index volatility from the corresponding aggregate total volatility, while "Idiosyncratic Volatility II" is calculated directly from the Fama and French (1993) three factor model.

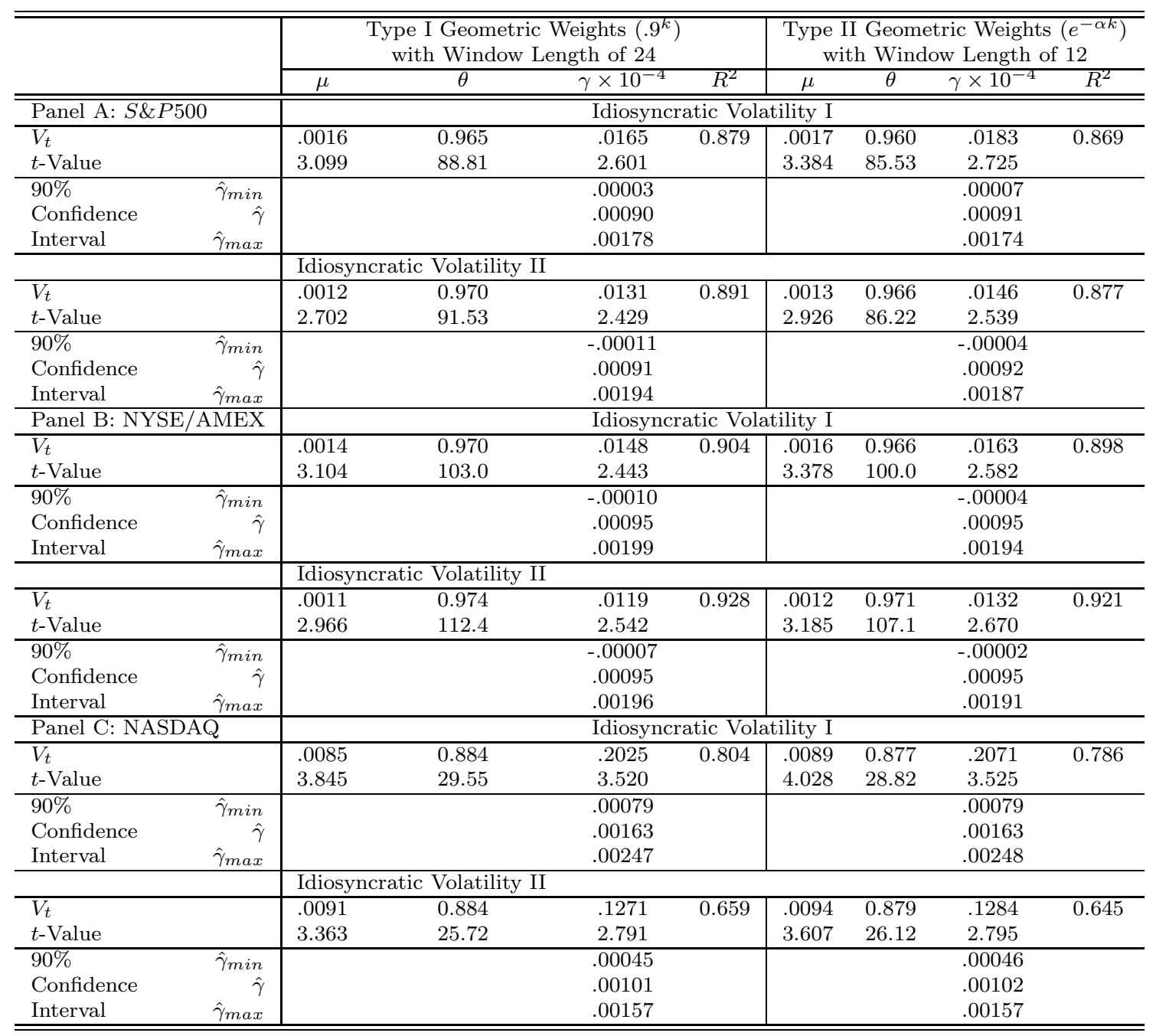


Table 7: Indices of Increased Institutional Investor Participation in U.S. Equity Markets

This table shows the increase in institutional participation in the market from 1950 through 1998.

\begin{tabular}{c||c|c|c}
\hline \hline Year & $\begin{array}{c}\text { Percent of Total Equity Held } \\
\text { by Institutional Investor }{ }^{1}\end{array}$ & $\begin{array}{c}\text { NYSE Block Transaction as } \\
\text { Percent of Total Reported Volume }{ }^{2}\end{array}$ & $\begin{array}{c}\text { Turnover Rate NYSE } \\
\left(\frac{\text { Reported Share Volume }}{\text { Shares Listed }}\right)\end{array}$ \\
\hline 1950 & 6.1 & NA & 23.0 \\
1970 & 26.7 & 15.4 & 19.0 \\
1990 & 44.1 & 49.6 & 46.0 \\
1998 & 49.6 & 48.7 & 76.0 \\
\hline \hline
\end{tabular}

${ }^{1}$ Source: Federal Reserve Board "Flow of Funds."

${ }^{2}$ Source: New York Stock Exchange Fact Book, Annual Editions

Table 8: Cross-Sectional Regressions of Idiosyncratic Volatility on Institutional Ownership and Size

This table shows the relationship between volatility, institutional ownership, and the size (capitalization) of individual stocks using partially adaptive estimators.

\begin{tabular}{|c|c|c|c|c|c|c|}
\hline \multirow[b]{2}{*}{ Year } & \multirow{2}{*}{$\begin{array}{c}\text { Dependent } \\
\text { Variable }\end{array}$} & \multicolumn{2}{|c|}{ 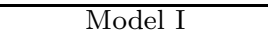 } & \multicolumn{3}{|c|}{ Model II } \\
\hline & & Ownership & $R^{2}$ & Ownership & $\log ($ Size $)$ & $R^{2}$ \\
\hline \multirow{3}{*}{1989} & $\overline{l o g}\left(V_{\text {idio. }}\right)$ & .00228 & 0.012 & $\overline{.00189}$ & $\overline{-. .284}$ & $\overline{0.224}$ \\
\hline & $(S t d . E)$ & $(.00091)$ & & $(.00079)$ & $(.0238)$ & \\
\hline & $p-$ Value & 0.013 & & 0.017 & 0.000 & \\
\hline \multirow{3}{*}{1990} & $\log \left(V_{\text {idio. }}\right)$ & .00127 & 0.002 & .00060 & -.411 & 0.389 \\
\hline & $(S t d . E)$ & $(.00129)$ & & $(.00103)$ & $(.0293)$ & \\
\hline & $p-$ Value & 0.326 & & 0.559 & 0.000 & \\
\hline \multirow{3}{*}{1991} & $\log \left(V_{\text {idio. }}\right)$ & .00353 & 0.021 & .00206 & -.361 & 0.349 \\
\hline & $(S t d . E)$ & $(.00109)$ & & $(.00099)$ & $(.0256)$ & \\
\hline & $p-$ Value & 0.001 & & 0.038 & 0.000 & \\
\hline \multirow{3}{*}{1992} & $\overline{l o g}\left(V_{\text {idio. }}\right)$ & .00388 & 0.025 & .00157 & -.325 & 0.244 \\
\hline & $(S t d . E)$ & $(.00124)$ & & $(.00107)$ & $(.0268)$ & \\
\hline & $p-$ Value & 0.018 & & 0.144 & 0.000 & \\
\hline \multirow{3}{*}{1993} & $\overline{l o g}\left(V_{\text {idio. }}\right)$ & .00323 & 0.023 & .00241 & -.209 & 0.151 \\
\hline & $(S t d . E)$ & $(.00038)$ & & $(.00095)$ & $(.0284)$ & \\
\hline & $p-$ Value & 0.000 & & 0.011 & 0.000 & \\
\hline \multirow{3}{*}{1994} & $\log \left(V_{\text {idio. }}\right)$ & .00354 & 0.035 & .00236 & -.201 & 0.175 \\
\hline & $(S t d . E)$ & $(.00079)$ & & $(.00084)$ & $(.0251)$ & \\
\hline & $p-$ Value & 0.000 & & 0.005 & 0.000 & \\
\hline \multirow{3}{*}{1995} & $\log \left(V_{\text {idio. }}\right)$ & .00610 & 0.070 & .00558 & -.111 & 0.098 \\
\hline & $(S t d . E)$ & $(.00087)$ & & $(.00091)$ & $(.0336)$ & \\
\hline & $p-$ Value & 0.000 & & 0.000 & 0.001 & \\
\hline \multirow{3}{*}{1996} & $\log \left(V_{\text {idio. }}\right)$ & .00561 & 0.056 & .00506 & -.081 & 0.068 \\
\hline & $(S t d . E)$ & $(.0082)$ & & $(.00082)$ & (.0110) & \\
\hline & $p-$ Value & 0.000 & & 0.000 & 0.000 & \\
\hline \multicolumn{7}{|c|}{ Pooling individual stocks over the whole sample period } \\
\hline 1989 & $\log \left(V_{\text {idio. }}\right)$ & .00359 & 0.023 & .00240 & -.261 & 0.189 \\
\hline to & $(S t d . E)$ & $(.00037)$ & & $(.00036)$ & $(.0104)$ & \\
\hline 1996 & $p-$ Value & 0.000 & & 0.000 & 0.000 & \\
\hline \multicolumn{7}{|c|}{ Pooling industry portfolios over the whole sample period } \\
\hline 1989 & $\log \left(V_{\text {idio. }}\right)$ & 1.596 & 0.336 & 1.387 & -.093 & 0.383 \\
\hline to & $(S t d . E)$ & $(0.232)$ & & $(0.238)$ & $(0.035)$ & \\
\hline 1996 & $p-$ Value & 0.000 & & 0.000 & 0.000 & \\
\hline
\end{tabular}




\section{Table 9: Cross-Sectional Regressions of Idiosyncratic Volatility on Long-term}

\section{Growth and Size}

This table shows the relationship between idiosyncratic volatility, forecasted long-term earning growth, and size of individual stocks. A nonlinear least square method is used in estimating the two-segment model where the turning point $c$ is also estimated simultaneously. In partial sample regressions, only sample observations that satisfy the condition of $g_{i}>c$ are used. "**" denotes the number of firms in this subsample. Standard deviations of estimates are in the brackets

\begin{tabular}{|c|c|c|c|c|c|c|c|c|c|c|c|}
\hline \multirow[b]{3}{*}{ Year } & \multirow{3}{*}{$\begin{array}{c}\text { Number } \\
\text { of } \\
\text { Firms }\end{array}$} & \multicolumn{5}{|c|}{$\log \left(V_{\text {idio., }, i}\right)=\alpha_{0}+\gamma_{0} g_{i}+\delta_{0} \log ($ Size $)$} & \multicolumn{2}{|c|}{$\log \left(V_{\text {idio. }, i}\right)=$} & \multicolumn{3}{|c|}{ 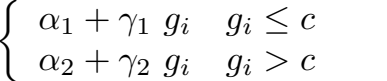 } \\
\hline & & \multicolumn{2}{|c|}{ Without Size } & \multicolumn{3}{|c|}{ With Size } & \multicolumn{3}{|c|}{2 Segment OLS } & \multicolumn{2}{|c|}{ Partial Sample } \\
\hline & & $\gamma_{0}$ & $R^{2}$ & $\gamma_{0}$ & $\delta_{0}$ & $R^{2}$ & $\gamma_{1}$ & $\gamma_{2}$ & $c$ & $\gamma_{2}$ & $R^{2}$ \\
\hline 1986 & $\begin{array}{l}1595 \\
1591^{*}\end{array}$ & $\begin{array}{l}.985 \\
(.047)\end{array}$ & 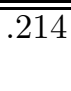 & $\begin{array}{c}.682 \\
(.043)\end{array}$ & $\begin{array}{c}-.053 \\
(.0023)\end{array}$ & 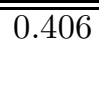 & $\begin{array}{l}-0.673 \\
(2.730)\end{array}$ & $\begin{array}{l}1.005 \\
(.047)\end{array}$ & $\begin{array}{l}.0051 \\
(.0042)\end{array}$ & $\begin{array}{l}1.005 \\
(.047)\end{array}$ & 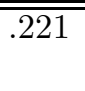 \\
\hline 1987 & $\begin{array}{c}1655 \\
1634^{*}\end{array}$ & $\begin{array}{l}.906 \\
(.051)\end{array}$ & .162 & $\begin{array}{l}.593 \\
(.045)\end{array}$ & $\begin{array}{c}.056 \\
(.0022)\end{array}$ & 0.402 & $\begin{array}{l}-4.033 \\
(2.480)\end{array}$ & $\begin{array}{l}0.971 \\
(.051)\end{array}$ & $\begin{array}{l}.0071 \\
(.0045)\end{array}$ & $\begin{array}{c}.971 \\
(.051)\end{array}$ & .181 \\
\hline 1988 & $\begin{array}{c}1700 \\
1505^{*}\end{array}$ & $\begin{array}{l}.724 \\
(.052)\end{array}$ & .103 & $\begin{array}{l}.532 \\
(.042)\end{array}$ & $\begin{array}{c}-.066 \\
(.0022)\end{array}$ & 0.420 & $\begin{array}{l}-7.832 \\
(.609)\end{array}$ & $\begin{array}{l}0.875 \\
(.055)\end{array}$ & $\begin{array}{l}.0471 \\
(.0049)\end{array}$ & $\begin{array}{l}.875 \\
(.055)\end{array}$ & .142 \\
\hline 1989 & $\begin{array}{c}1762 \\
1526^{*}\end{array}$ & $\begin{array}{l}.723 \\
(.061)\end{array}$ & .075 & $\begin{array}{l}.513 \\
(.048)\end{array}$ & $\begin{array}{c}.069 \\
(.0022)\end{array}$ & 0.419 & $\begin{array}{l}-9.356 \\
(.633)\end{array}$ & $\begin{array}{l}1.038 \\
(.068)\end{array}$ & $\begin{array}{l}.0498 \\
(.0051)\end{array}$ & $\begin{array}{l}1.038 \\
(.067)\end{array}$ & .135 \\
\hline 1990 & $\begin{array}{c}1804 \\
1569^{*}\end{array}$ & $\begin{array}{l}.742 \\
(.062)\end{array}$ & .074 & $\begin{array}{l}.541 \\
(.049)\end{array}$ & $\begin{array}{c}.072 \\
(.0021)\end{array}$ & 0.436 & $\begin{array}{l}-11.16 \\
(.663)\end{array}$ & $\begin{array}{l}1.037 \\
(.067)\end{array}$ & $\begin{array}{l}.0465 \\
(.0054)\end{array}$ & $\begin{array}{l}1.037 \\
(.067)\end{array}$ & .132 \\
\hline 1991 & $\begin{array}{c}1818 \\
1529^{*}\end{array}$ & $\begin{array}{l}.589 \\
(.058)\end{array}$ & .053 & $\begin{array}{c}.531 \\
(.044)\end{array}$ & $\begin{array}{l}.074 \\
(.0020)\end{array}$ & 0.458 & $\begin{array}{l}-12.01 \\
(.707)\end{array}$ & $\begin{array}{l}1.021 \\
(.063)\end{array}$ & $\begin{array}{l}.0427 \\
(.0055)\end{array}$ & $\begin{array}{l}1.021 \\
(.060)\end{array}$ & .161 \\
\hline 1992 & $\begin{array}{c}1812 \\
1514^{*}\end{array}$ & $\begin{array}{l}.714 \\
(.059)\end{array}$ & .076 & $\begin{array}{c}.633 \\
(.046)\end{array}$ & $\begin{array}{l}-.070 \\
(.0021)\end{array}$ & 0.435 & $\begin{array}{l}-11.55 \\
(.664)\end{array}$ & $\begin{array}{l}1.186 \\
(.064)\end{array}$ & $\begin{array}{l}.0447 \\
(.0055)\end{array}$ & $\begin{array}{l}1.186 \\
(.061)\end{array}$ & .200 \\
\hline 1993 & $\begin{array}{c}1929 \\
1671^{*}\end{array}$ & $\begin{array}{l}.797 \\
(.053)\end{array}$ & .106 & $\begin{array}{c}.648 \\
(.041)\end{array}$ & $\begin{array}{l}-.068 \\
(.0019)\end{array}$ & 0.467 & $\begin{array}{r}-15.18 \\
(.904)\end{array}$ & $\begin{array}{l}1.334 \\
(.056)\end{array}$ & $\begin{array}{l}.0317 \\
(.0048)\end{array}$ & $\begin{array}{l}1.334 \\
(.055)\end{array}$ & .258 \\
\hline 1994 & $\begin{array}{c}2039 \\
1735^{*}\end{array}$ & $\begin{array}{c}.945 \\
(.050)\end{array}$ & .151 & $\begin{array}{c}.771 \\
(.040)\end{array}$ & $\begin{array}{c}-.064 \\
(.0019)\end{array}$ & 0.467 & $\begin{array}{r}-7.748 \\
(.531)\end{array}$ & $\begin{array}{l}1.350 \\
(.056)\end{array}$ & $\begin{array}{c}.0549 \\
(.0001)\end{array}$ & $\begin{array}{l}1.350 \\
(.054)\end{array}$ & .266 \\
\hline 1995 & $\begin{array}{c}2120 \\
1789^{*}\end{array}$ & $\begin{array}{l}1.007 \\
(.044)\end{array}$ & .196 & $\begin{array}{c}.827 \\
(.036)\end{array}$ & $\begin{array}{c}-.063 \\
(.0019)\end{array}$ & 0.468 & $\begin{array}{r}-8.656 \\
(.564)\end{array}$ & $\begin{array}{l}1.327 \\
(.050)\end{array}$ & $\begin{array}{c}.0543 \\
(.0001)\end{array}$ & $\begin{array}{l}1.327 \\
(.049)\end{array}$ & .289 \\
\hline & & & & Pooling & individu & $\overline{\text { stocl }}$ & ver the & hole sa & ple peric & & \\
\hline $\begin{array}{c}1986 \text { to } \\
1995\end{array}$ & $\begin{array}{c}18234 \\
16005^{*}\end{array}$ & $\begin{array}{l}0.806 \\
(.017)\end{array}$ & & $\begin{array}{c}.627 \\
(.014)\end{array}$ & $\begin{array}{c}-.067 \\
(.0007)\end{array}$ & 0.435 & $\begin{array}{r}-10.78 \\
(.225)\end{array}$ & $\begin{array}{l}1.124 \\
(.018)\end{array}$ & $\begin{array}{c}.0448 \\
(.0001)\end{array}$ & $\begin{array}{l}1.124 \\
(.018)\end{array}$ & .196 \\
\hline
\end{tabular}


Figure 1 The Volatility of Individual Stocks (1963-1998)

This figure shows the monthly volatility for the most volatile stocks in the market.
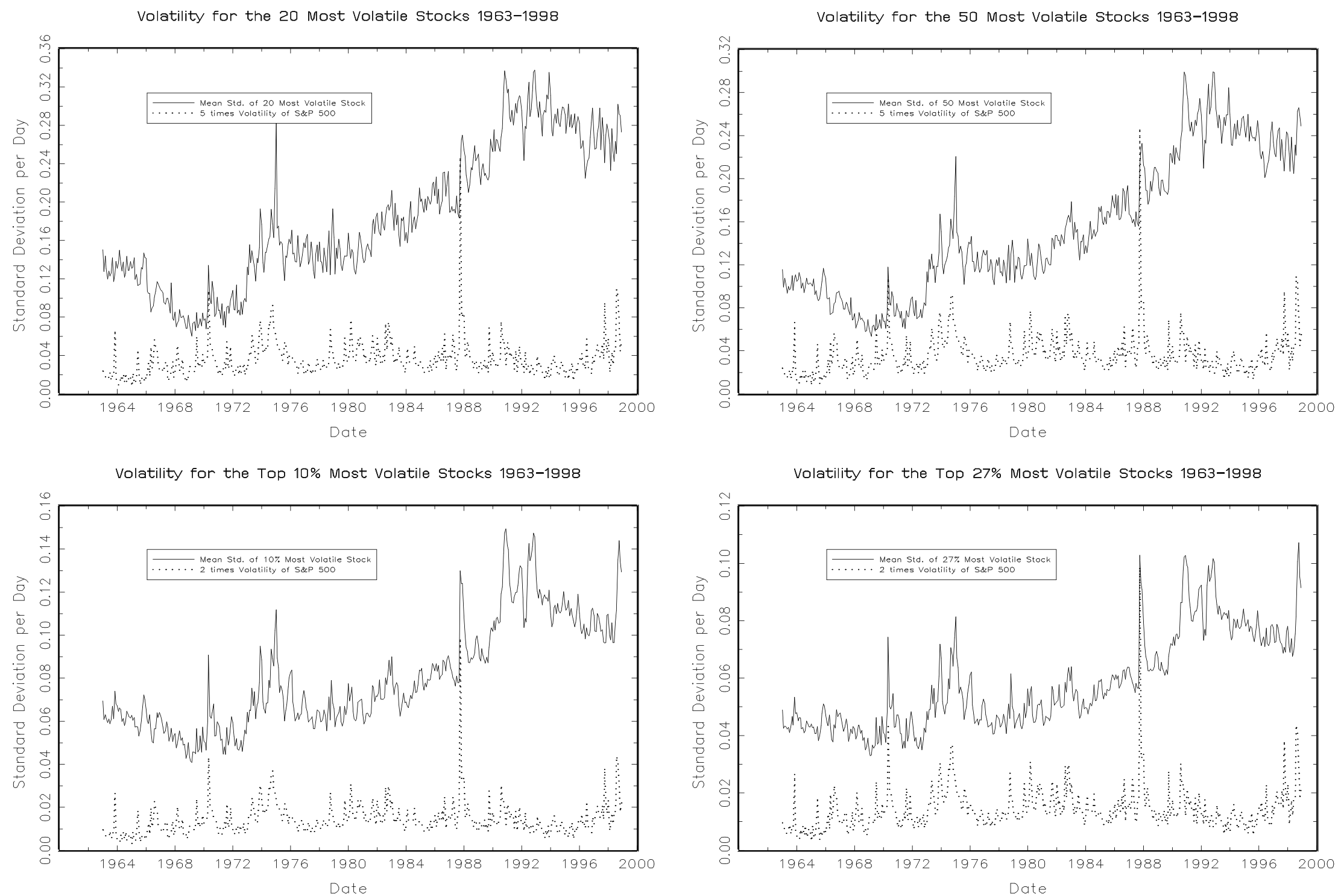
Standard Deviation per Month

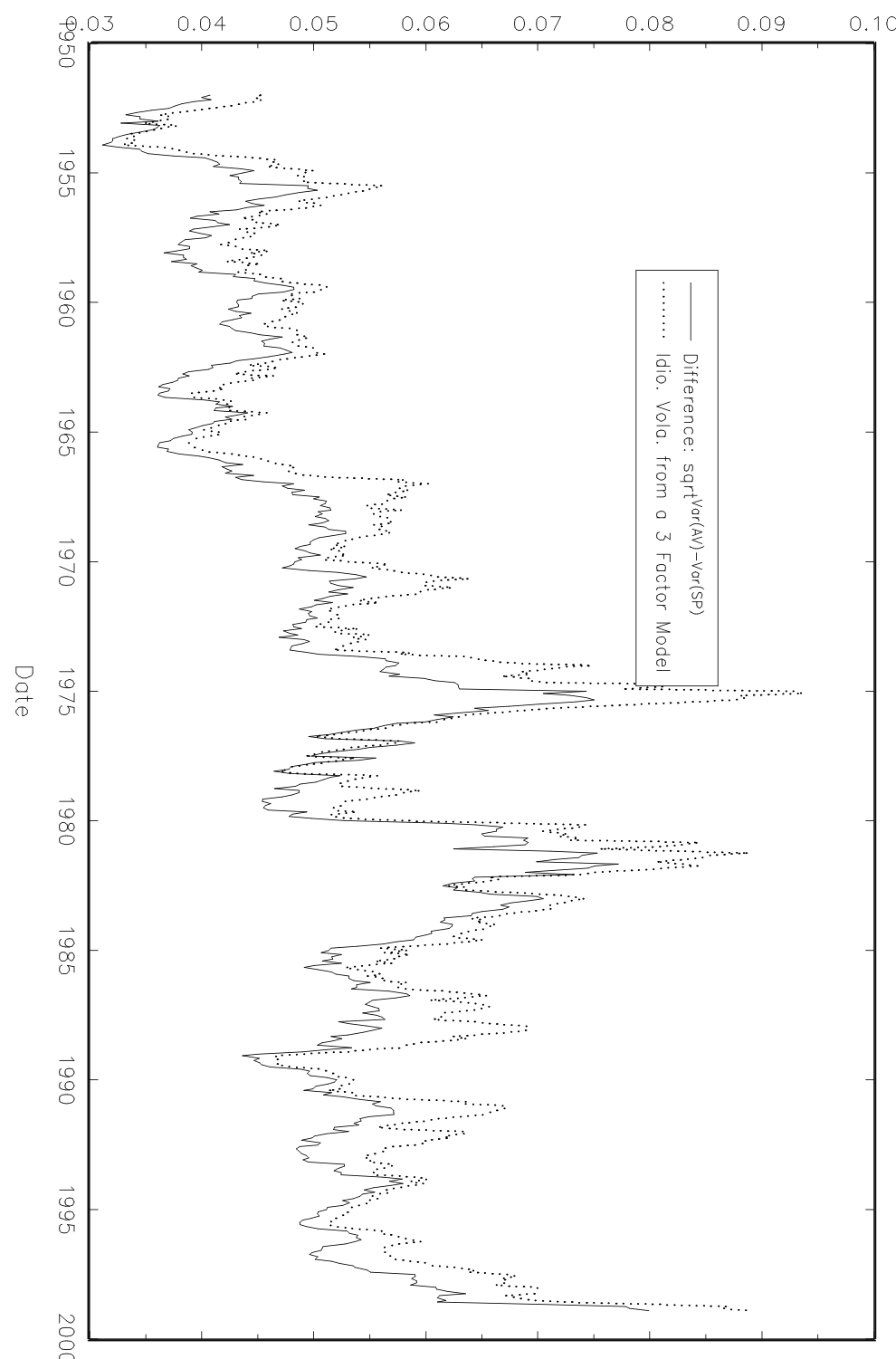

Standard Deviation per Month

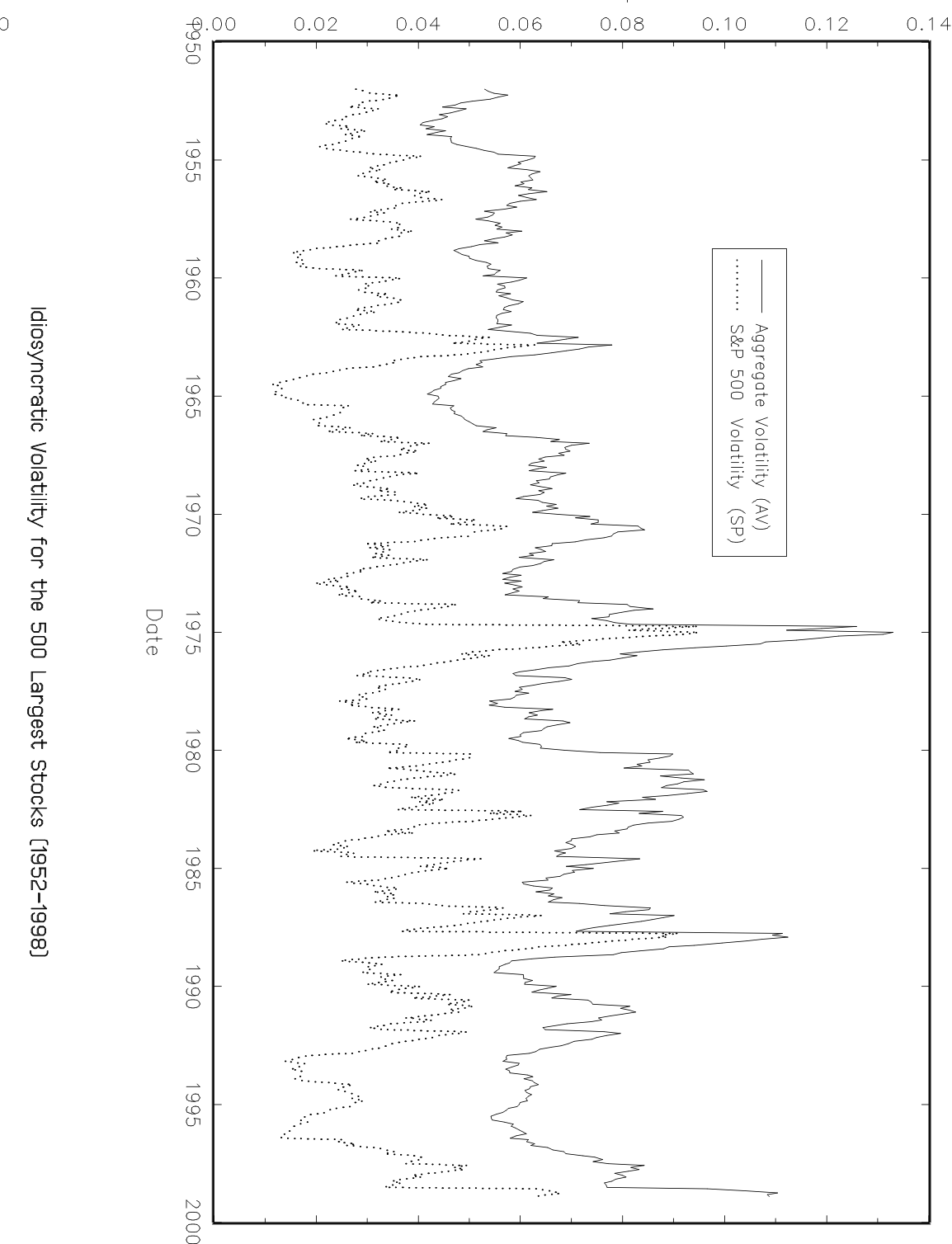

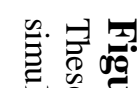

政

$\therefore$. vo

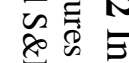

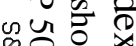

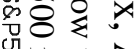

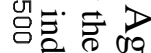

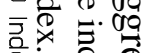

高

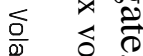

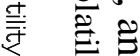

क

品

遂

年

के

竞

产

o

응

(a)

每

i

落 है.

क

额

道

递

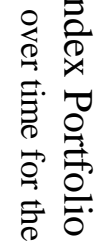


Figure 3

Aggregate Idiosyncratic Volatility [1952-1998]

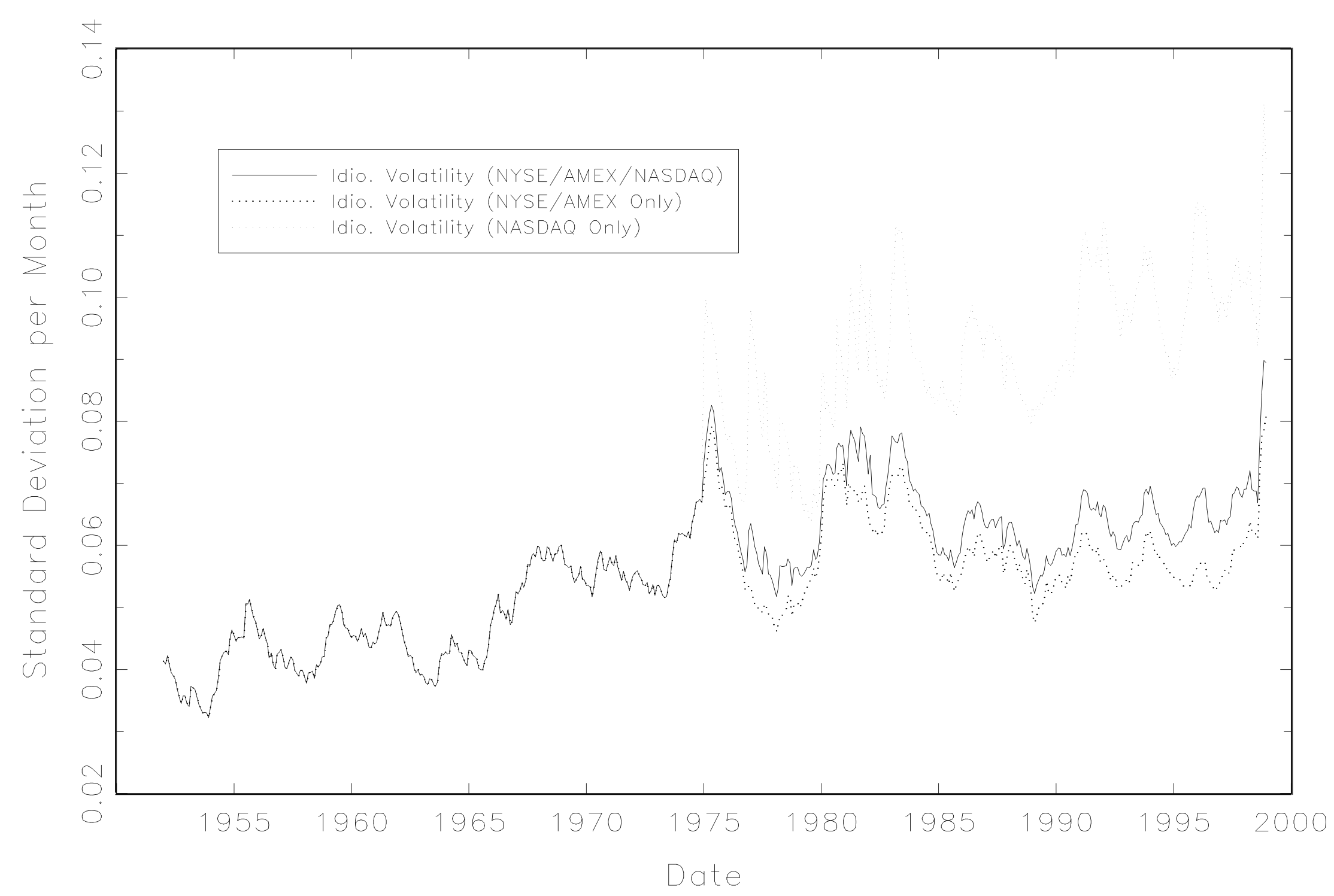




\section{Figure 4}

Idiosyncratic Volatility \& Long Term Earning Growth for Individual Stocks [1995]

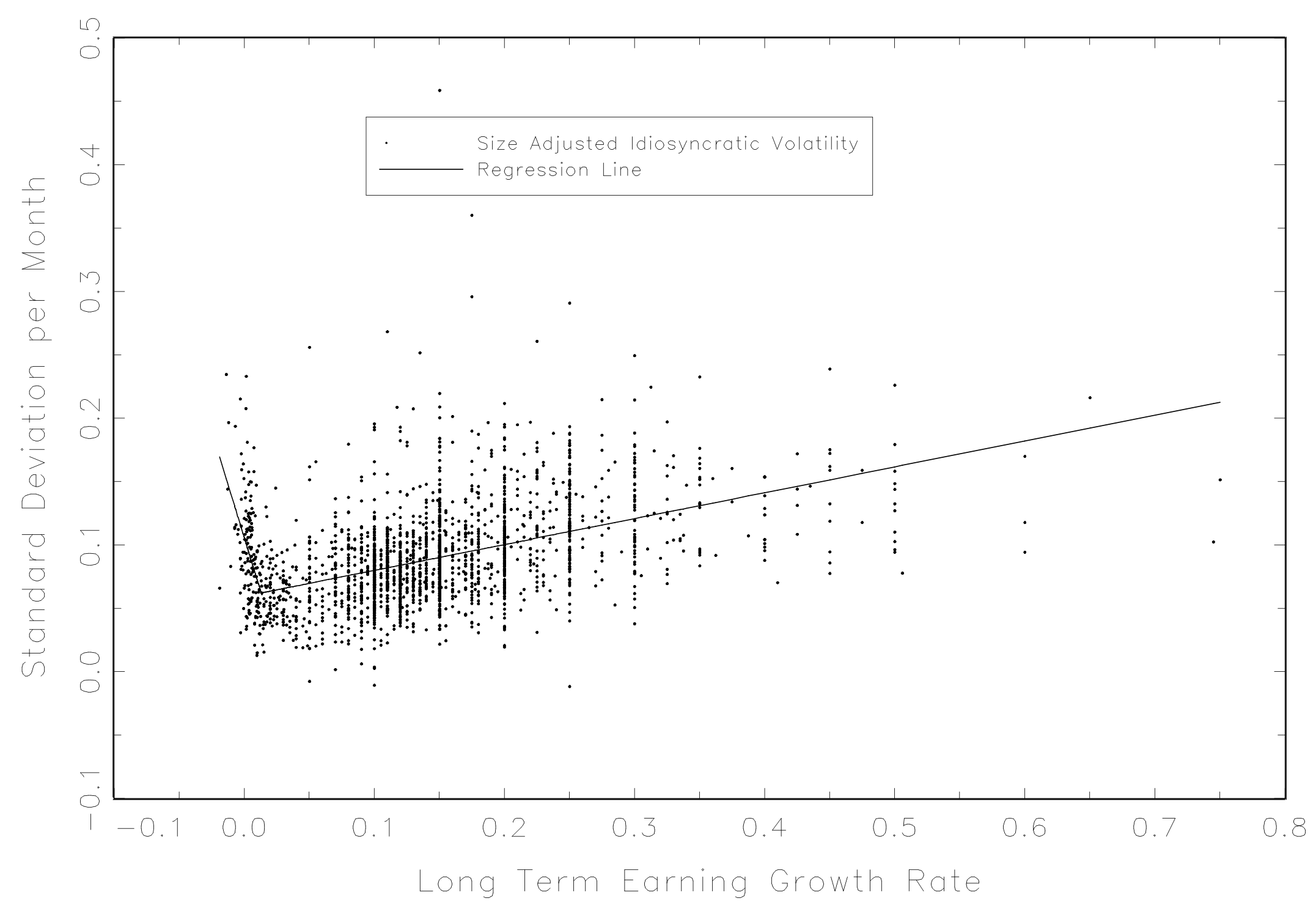

